\title{
Links between language and executive functions in Swedish preschool children: A pilot study
}

\author{
Signe Tonér ${ }^{\star}$ (D) and Tove Nilsson Gerholm \\ Stockholm University \\ ${ }^{\star}$ Corresponding author. E-mail: signe.toner@ling.su.se
}

(Received 29 August 2018; revised 11 August 2020; accepted 09 October 2020; first published online 07 December 2020)

\begin{abstract}
Language skills and executive functions $(\mathrm{EF})$ undergo rapid development during preschool years and are foundational for a wide range of life outcomes but little is known of the connections between language and EF in Swedish, typically developing children. The current pilot study included 47 mono- and multilingual children aged 4-6 and aimed at describing the relationship between language and EF and investigating potential associations to age, sex, bi-/multilingualism, socioeconomic status (SES), and aspects of preschool attendance. Measures of language and EF correlated with one another to a large extent, but also showed some differentiation, suggesting a specific link between morphosyntactic ability and inhibition. Age was a significant predictor of most but not all measures. No significant effects of sex were found, with the exception for a female advantage in nonverbal communicative behavior, assessed by a novel rating paradigm. SES did not predict language or EF, and bi- and/or multilingual children did not differ from monolingual Swedish children on language or EF measures. Findings are discussed in relation to the connection between language and $\mathrm{EF}$ as well as to the needs of development of reliable language, $\mathrm{EF}$, and communication measures for use in the Swedish context.
\end{abstract}

Keywords: language; executive function; early childhood; assessment; preschool

Language skills and executive functions (EF) have been shown to predict children's outcomes concerning academic success, social relationships and quality of life (e.g., Blair \& Raver, 2015; Bull et al., 2008; Clark et al., 2013; Hoff, 2003; Hoff-Ginsberg, 1991; McClelland et al., 2013; Moffitt et al., 2011; Sarsour et al., 2010). During the preschool years, children's language skills undergo rapid development as vocabulary grows quickly, children's use of syntactic rules becomes more adultlike, and the ability to use language in discourse improves (e.g., Odato, 2013; Song et al., 2015; Tomasello, 2000). Early childhood is also characterized by substantial unrestricted re-use, distribution, and reproduction in any medium, provided the original work is properly cited. 
improvements in EF, an array of organizing and self-regulating behaviors, often described as consisting of three interrelated core skills: working memory, shifting/cognitive flexibility, and inhibition (e.g., Diamond, 2013; Miyake et al., 2000). Our understanding of how different aspects of language relate to EF-or which part of EF they relate to-is limited. Improved knowledge of children's language and $\mathrm{EF}$ is important because we know that these skills are trainable (Abel et al., 2015; Diamond \& Lee, 2011) and predict important life outcomes. A prerequisite for such insights is that we can measure language and EF in a reliable way.

In this pilot study we examine an array of language and EF skills in 47 mono- and multilingual Swedish children aged 4-6 to shed further light on relationships between aspects of these abilities. Furthermore, we investigate potential associations of language and EF to age, sex, socioeconomic status (SES), presence of additional/ other language(s) than Swedish in the home, and aspects of preschool attendance to guide future hypotheses about the development of language and EF in the Swedish context and to enable comparisons with studies on other populations. Including a wider range of language measures than many previous studies allows for deeper understanding of the relationship between language and EF. Increased knowledge of young Swedish children's language and EF in relation to the social context has potential applications with regard to current preschool practices in Sweden.

\section{Language Assessment}

"Language" can be seen as an umbrella term for a number of skills, such as productive and receptive vocabulary, morphosyntactic abilities, and pragmatic or communicative skills. A challenge for researchers as well as clinicians and special education teachers is the lack of reliable Swedish assessment materials that can be used for children 4-6 years of age (in Sweden, children start school the year they turn 6 years old). An additional problem is that available instruments most often have monolingual norms and are thus not suitable for use with bi- or multilingual children, who comprise at least 25 percent of children in Sweden (Statistics Sweden, 2015).

The only comprehensive test battery that was available in Sweden at the point of data collection for the current study was the Clinical Evaluation of Language Fundamentals (CELF-4; Semel et al., 2003) with Scandinavian norms from age $5 .^{1}$ More recently, Swedish norms were published for the New Reynell Developmental Language Scales, covering the age range 2- to 7-year-old children, including a multilingual toolkit but no bi- or multilingual norms (Lundeborg Hammarström et al., 2017).

Many instruments are often specific to some subdomain of language, which entails that several tests need to be administered to get a representative conception of a child's language skills in a broader sense. Assessment materials with such a more limited scope include Test of Receptive Grammar (TROG; Bishop, 2003) with Swedish norms for ages 4.0-12.11, or Gramba, assessing productive grammar skills with a main focus on inflectional morphology, with Swedish norms for ages 3-6 (Hansson \& Nettelbladt, 2010). The Peabody Picture Vocabulary Test (PPVT; Dunn \& Dunn, 2007) is a well-known test for receptive vocabulary that in its original English version can be used across the life span, however, there is no standardized Swedish version or translation. Cross-linguistic lexical tasks, primarily LITMUS-CLT, are available in a wide range of languages and are considered suitable for assessing vocabulary in children aged 3-6 (e.g., Haman et al., 2015). CLTs have been used for investigating 
comprehension and/or production of nouns and verbs in monolingual Swedish children (Haman et al., 2017; Lindgren, 2018) as well as bilingual Swedish-German and Swedish-Turkish children (Bohnacker et al., 2016; Lindgren, 2018). Norming studies are yet to be conducted and data from Swedish children, including associations to SES were published after the data collection of the current study.

An alternative for assessing vocabulary size as well as other aspects of language is to use parental questionnaires adapted for different age groups and languages (e.g., CDI, McArthur \& Bates Communicative Developmental Inventories; Fenson et al., 1994). The Swedish version of CDI-III includes scales on vocabulary, grammar, and metalinguistic awareness and was recently validated up to age 4.0 (Eriksson, 2017). Swedish CDI-III data include assessments from 1,134 parents. Age and gender significantly predicted vocabulary and syntax (girls scored higher than boys), whereas SES did not significantly predict parental ratings. The sample was somewhat skewed toward higher SES but the author suggests that the high attendance to publicly financed preschools may moderate SES-related language differences (ibid.)

An alternative way to assess children's language skills is to use narrative language samples and investigate children's language in connected speech. This strategy can be employed from an early age, as children start producing minimal narratives at around 2.6 years of age (Labov \& Waletzky, 1967). Moreover, narrative assessment provides rich linguistic information concerning form, content, and use of language and is considered an ecologically valid assessment of communicative competence (e.g., Botting, 2002). There are narrative elicitation materials or tasks that have been used in research to acquire narrative data, most often by letting the participant generate a story based on some kind of visual material, or by telling a story to the participant that he/she subsequently retells it in his/her own words. An example of a material to generate children's stories is the Edmonton Narrative Norms Instrument (ENNI; Schneider et al., 2005). Furthermore, wordless picture books such as Frog, Where Are You? by Mayer (2003) have been widely used to elicit narratives in both children and adults from various linguistic and cultural backgrounds, including Swedish (e.g., Berman et al., 1994; Strömqvist \& Verhoeven, 2004), but samples in Swedish studies have usually been small and norms are not available. A material that allows for different elicitation modes, including both story generation and story retell, is LITMUS-MAIN, the Multilingual Assessment Instrument for Narratives (Gagarina et al., 2012; Gagarina et al., 2019), which has been used for Swedish mono- and bilingual children aged 4-7 (Bohnacker, 2016; Lindgren, 2018; Lindgren, 2019). In a longitudinal study of 17 4- to 7-year-old children using the BabyBirds/BabyGoats from LITMUS-MAIN, Lindgren (2019) found a developmental leap occurring in particular between the ages 4.4-5.10. Another narrative task, that focuses completely on story retell is the Bus Story Test (BST) that provides Swedish norms for children aged 3.119.0 years (Renfrew, 1995; Svensson \& Tuominen-Eriksson, 2002). BST has been used in Swedish clinical settings as well as in research on, for instance, children with autism spectrum disorders or ADHD (e.g., Johnels et al., 2013; Kjellmer et al., 2018) or children with cleft lip and palate (Klintö et al., 2015). For Swedish-speaking typically developing children, a significant correlation was found between the Bus Story's sentence length, number of subordinate clauses, and information measures and a picture arrangement task from WISC-III in a sample of 77 children in the age span 3.11 to 9.0 years old (Carlsson \& Södergård, 2014). 
Language is furthermore a social tool and a competent language user employs abilities such as adequate turn-taking, which in turn requires appropriate gaze behavior, use of gestures, body posture, and prosodic traits. Assessment of these "pragmatic" or "communicative" skills, requires access to both video and audio data and has seldom been included in research on typically developing children's language skills.

In summary, there is a shortage of comprehensive Swedish language assessment materials for children aged 4.0-6.0 years. Audio and video recordings of narrative language samples provides opportunities to extract information on an array of language and communication abilities.

\section{EF Assessment}

Similarly to language assessment, very few EF assessment materials are standardized or validated for Swedish children aged 4-6, exceptions being subtests of working memory included in the WPPSI-IV ${ }^{2}$ and one subtest assessing inhibition in NEPSY-II (Korkman et al., 2011). The assessment of EF is complex from a practical as well as a theoretical point of view. A plethora of instruments to assess EF in children are described in the literature (e.g., Carlson, 2005; Diamond, 2013, for summaries), but the same test/task may be described as assessing different aspects of EF, and one single task may require the recruitment of more than one EF component. For instance, the widely used Dimensional Change Card Sort task (DCCS) is often described as assessing cognitive flexibility/shifting (e.g., Diamond, 2013) but may also require working memory capabilities (Dajani \& Uddin, 2015) as well as inhibition (Kirkham \& Diamond, 2003). It has also been argued that adequate performance on a specific EF task can depend on different underlying processes (Ramscar et al., 2013) and that different forms of inhibition do not reflect the same underlying neural system (see e.g., Diamond, 2013, for a review). Despite the lack of agreement on how to describe EF tests, there is a growing consensus to treat EF as a unitary structure in early childhood because clear differentiation into the three core EF components shifting/cognitive flexibility, inhibition, and working memory appear to occur later in development (e.g., Fuhs \& Day, 2011; Wiebe et al., 2008). EF should preferably be assessed through a variety of tasks to capture different aspects of the construct (e.g., Diamond, 2013). However, this approach does not solve another, potentially problematic issue with regard to EF assessment, namely that children's achievement on performancebased EF tests does not always correspond to EF functioning in everyday life, as measured by behavioral ratings (e.g., Toplak et al., 2013, for a review).

To summarize, very few EF assessment materials are validated for Swedish children and there is no consensus with regard to which skill(s) a particular task really measures. A test battery should thus be designed to cover different parts of EF, regardless if the assumption of EF as unitary in early childhood is true or not.

\section{Suggested Relationships between Language Skills and EF}

Relationships between EF and different aspects of language skills are frequently reported and deficits in $\mathrm{EF}$ are common in children with language disorders (e.g., Gooch et al., 2016). However, the nature of the developmental relationship 
between EF and early language skills is still unclear. Good language skills have been suggested to help children in initiating and regulating behavior (Vallotton \& Ayoub, 2011; Zelazo \& Jacques, 1996), and it has been claimed that abstract language is key to succeeding at many EF tasks, particularly with regard to aspects of inhibition (Zelazo \& Frye, 1998; Zelazo et al., 1998). Recent research comparing nonverbal EF skills in deaf and hearing children have shown that language had a mediating role in EF performance (Botting et al., 2017). However, there is also evidence that EF supports aspects of language skills. Retelling a story has been argued to rely on EF in a specific way: The task places significant demands on verbal working memory because the narrator needs to activate concepts and schemas outside of immediate short-term memory to both process and recall the material (Gabig, 2008). BlainBrière et al. (2014), who investigated EF and narrative skills in a sample of 4- to 5 -year-olds, suggested that EF promotes the ability to produce utterances that are clearly understood.

Results from longitudinal studies are inconsistent with regard to the association, and potential causal relation, between EF and language skills. Many studies have included multiple measures of EF but only a single or very few measures of language skills. Weiland et al. (2014) showed that EF skills at the beginning of preschool predicted receptive vocabulary at the end of preschool, whereas receptive vocabulary did not predict EF. However, Fuhs and Day (2011) who included both receptive and expressive vocabulary, found that verbal ability predicted longitudinal change in EF. Gooch and colleagues (2016) included both vocabulary measures and measures of syntactic comprehension and found strong associations between language and $\mathrm{EF}$ at each time point during preschool and early school years, but little evidence of significant reciprocal influences between the constructs. Slot and von Suchodoletz (2017), who included measures of vocabulary as well as receptive and productive grammar, found that language was a better predictor for EF than vice versa in a sample of German preschoolers aged 3-4. An alternative interpretation of findings regarding concurrent as well as longitudinal relationships between language and EF is that tests of "language skills" and "EF" both tap into general cognitive abilities and/or that there is a general task impurity problem when attempting to assess these skills in isolation.

Previous work regarding the relationship between language and EF in Swedish preschool-aged children is scarce and has primarily investigated these skills in atypical populations, such as children with hydrocephalus (Lindquist et al., 2008) or children with epilepsy (Rejnö-Habte Selassie et al., 2008) and/or has focused more on either language, for instance, narrative ability in children with autism spectrum disorders (Johnels et al., 2013) or EF, such as relations between $\mathrm{EF}$ and hyperactivity/impulsivity in Swedish preschoolers with ADHD symptoms (Brocki et al., 2010).

To summarize, relationships between aspects of language and EF are frequently reported. However, previous research on the relationship between language and $\mathrm{EF}$ in other settings has often limited "language" to measures of vocabulary. Language skills should preferably be represented by a more varied set of linguistic abilities to enable further understanding of the language-EF association. There is a knowledge gap regarding language and EF skills in typically developing Swedish children. 


\section{Demographic Factors Related to Language and EF}

In the current study, the following demographic variables were investigated in relation to the child's language and EF measures: age, sex, bi- or multilingualism, parental SES (income and educational level), preschool enrollment, and preschool attendance.

\section{Age}

Language and EF are related to age during early childhood and reliable assessment materials should be sensitive to this maturation. It should however be noted that the predictive value of age alone on children's cognitive performance is quite limited (see e.g., Eriksen et al., 2013; McKean et al., 2017). While it is generally agreed that large developmental changes take place between a child's fourth and fifth birthday (e.g., Brown \& Jernigan, 2012), relatively little is known of the exact time scale and potential variability with regard to language and EF in typically developing Swedish children. For Swedish, there are language assessment materials available that reflect the expected age-related maturation of linguistic abilities, either in the form of standardized or norm-based published tests used for clinical and/or special education purposes, or in the form of instruments or tasks that have been used in research including Swedish children, thus providing comparative data (see previous section on language assessment). For EF, assessment materials with age norms for Swedish are scarce (see previous section on EF assessment).

\section{Sex}

In spite of the popular belief that girls are better language learners than boys, previous results regarding sex differences in emerging language skills are not consistent and may depend on which aspect(s) of language that has been the focus of investigation (e.g., Barbu et al., 2015; Lange et al., 2016). Swedish studies on sex-related differences in language skills are scarce. Eriksson et al. (2012) did, however, find a female advantage with regard to parent-reported vocabulary in 13,783 children aged 8-30 months across 10 language communities, including Swedish, suggesting that sex-related language differences may be present from an early age. A large-scale German study including 3- to 6-year-old children found that girls did better than boys in several linguistic domains, but effect sizes were small (Lange et al., 2016). With respect to EF, results are inconsistent: girls outperform boys in a number of studies (e.g., Fuhs \& Day, 2011; Mulder et al., 2014), whereas other studies, in particular those conducted outside the United States, have not found sex-related differences in EF (e.g., Gestsdottir et al., 2014; Slot \& von Suchodoletz, 2017). A Swedish study revealed no sex-related EF differences in a sample of 92 6-to 13-year-old children, except that boys did better than girls with regard to the speed/arousal dimension, comprising information about response times and omission errors on tasks primarily measuring inhibitory skills (Brocki \& Bohlin, 2004). Recently, Grissom and Reyes (2019), evaluated sex differences in EF in both humans and rodents and concluded that sex-related EF differences are small or nonexisting.

\section{Bi-/multilingualism}

In Sweden, at least 25 percent of children in preschools are considered bilingual (Statistics Sweden, 2015). Because bi- and multilingual children's language knowledge 
is distributed over two or more languages, performance in either language is not expected to be equal to that of monolingual peers. Neither is it expected that both/ all languages develop in parallel and performance may furthermore differ depending on how closely related the languages are (e.g., Lindgren, 2018). Thordardottir (2011) conducted a study including Canadian French-English bilingual children who were matched on SES and nonverbal cognition and found that vocabulary in each language was associated with amount of exposure. Regarding narrative ability, Bohnacker (2016) investigated narrative comprehension and macrostructure production in Swedish-English bilingual children and found an effect of age, but not of language, suggesting that story structure is similar across a child's languages. With regard to EF, it has been claimed that bilingual children show earlier maturation of executive processes than monolingual peers (e.g., Adesope et al., 2010; Barac et al., 2016), but more recent meta-analyses do not support a bilingual advantage in EF (e.g., Dick et al., n.d.; Duñabeitia et al., 2014).

\section{Socioeconomic status}

Among the Swedish adult population, 83 percent of the adult Swedish population has at least high school education and the differences in income are among the smallest among OECD countries (OECD, 2017). However, children with at least one foreign-born parent are at higher risk of poverty than children with Swedish-born parents (SCB, 2017). It is well established that children from lower-SES backgrounds perform lower on cognitive and language tasks than children from more advantaged backgrounds (e.g., Ursache \& Noble, 2016). Since Hart and Risley's (1995) seminal study, it has been considered general knowledge that children from lower-SES backgrounds show delays in their language acquisition that are related to the quality of linguistic input from parents (see also Rindermann \& Baumeister, 2015). Calvo and Bialystok (2014) showed that parental SES made independent contributions to differences in language and EF performance in 6-year-old children, in both monolingual and bilingual children. A Danish study investigating predictors of intelligence at age 5 in a sample of 1,782 healthy children concluded that parental education should be included routinely in studies on cognitive development (Eriksen et al., 2013). Swedish studies investigating associations between SES and language and/or executive functions are rather scarce, but include a study on reading and literacy in 21415 -year-old students (Pajkin, 2014). Pajkin found that reading and literacy skills were correlated to cultural capital as measured through the child's rating of questions such as "we talk about books, films, theater etc. at home" and "my parents think it is important to exercise." Economic wealth did not affect the teenagers' results on reading and literacy tasks. A study on 224 Swedish children in the ages 7-8 (Andersson et al., 2019) compared the results on CELF-4 in relation to the children's multilingualism, the parents' educational level, the child's attendance to leisure-time center, and the SES of the neighborhood (based on information from the tax agency). The results were complex but indicate that a mixture of factors- having Swedish as L2, low parental education, not attending leisure-time center, and living in a low-SES neighborhood-contributed to children's low results on CELF-4. 


\section{Preschool enrollment and attendance}

Another potentially important factor in the Swedish context is that children in Sweden tend to start preschool as early as 1-2 years of age, which provides more opportunity for environmental influences from other than parental sources. In Sweden, children have a legal entitlement to 15 hours of weekly preschool attendance also when parents are unemployed or on parental leave with a younger sibling. Fees are heavily subsidized and 95 percent of children aged 4-5 attend preschool (SKR, 2018). To our knowledge, no Swedish studies have investigated how age at preschool enrollment or the amount of preschool time relates to individually assessed language and EF performance, even though such a vast majority of children attend preschool. There are also remarkably few international studies investigating the effects of age at preschool start and the amount of time spent at preschools. Loeb et al. (2007) however, showed that academic gains related to age at preschool start were significant for American children who enrolled in Head Start from 2 to 3 years of age, but not for children who started earlier. Based on results from an international systematic review (not including Sweden), Burger (2010) stated that in a majority of studies, preschool experience contributes to school readiness. However, the findings regarding age of enrollment and amount of time spent at preschools were inconclusive. Research regarding preschool in the Scandinavian context include a Norwegian study in which children who attended preschool were compared with children who did not (Havnes \& Mogstad, 2011). Authors concluded that subsidized childcare had strong positive effects on educational attainment and furthermore showed that children from lower SES backgrounds benefited the most from childcare (ibid.).

\section{The Current Study}

The aims of the current pilot study were: (a) to describe relationships between language and EF measures in a sample of 47 4- to 6-year-old children, monolingual as well as bi-/multilingual; and (b) to investigate possible associations between language and EF and the following demographic variables: age, sex, bi-/multilingualism, parental SES, and aspects of preschool attendance. The following research questions were formulated:

RQ 1. If, and in that case how do measures of narrative language, parent-rated vocabulary/morphology, measures of $\mathrm{EF}$, and communication ratings correlate with one another?

RQ 2. To what extent can demographic variables (age, sex, bi-/multilingualism, parental SES, age at preschool enrollment, and current time/week at preschool) predict language and EF scores?

Two separate rounds of testing were conducted, allowing for adjustments in choice of materials and procedure, which was important because many of the materials had not previously been used in the Swedish context. We administered a narrative task and EF tasks, rated children's communication on the basis of video-recordings and collected additional information using parental questionnaires. We predicted that our language measures correlate more with one another than 
with measures of $\mathrm{EF}$ and vice versa (RQ 1). We predicted that all EF measures are significantly associated because they possibly measure the same latent EF construct (RQ 1). We explored the relationship between different aspects of language and EF and hypothesized that language and EF correlate, in accordance with a vast body of previous studies that have shown clear associations between language and EF (RQ 1). Age was hypothesized to predict language as well as EF measures. Monolingual Swedish children were predicted to show an advantage in language compared to bi-/multilingual children. Because previous results regarding eventual differences between girls and boys and between monolinguals and bilinguals in EF are mixed, no specific predictions were made. SES was hypothesized to play a role in models predicting both language and EF performance (RQ 2). No specific hypotheses were made with regard to age at preschool start and weekly preschool attendance.

\section{Materials and Methods}

\section{Participants}

Ethics approval was obtained from the Regional Ethical Review Board (https://ki.se/ en/orgid/303872, DNR nr: 2015/1664-31/5) and data was collected during spring 2016. Participants were recruited from three preschools in a suburban area in the Stockholm region with a lower average educational level but higher average income than the country as a whole (SCB, 2018). The preschools had an ongoing collaboration with the university and should be considered a convenience sample. Inclusionary criteria were parental informed consent, that the child was or turned 4 years of age at the start of data collection, and that he/she was able to follow simple instructions in Swedish, leading to 51 children eligible for participation, of which three children were absent and one child chose not to participate. The final sample thus consisted of 47 children ( 24 boys and 23 girls, mean age 5.3 years, age range $4.0-6.4$ years). For demographic details, see also Table 1. Children were considered bi- or multilingual if one or more languages than Swedish were spoken in the home. At least half of the children came from homes in which additional/other languages than Swedish were spoken; parents of 23 children stated that a language other than Swedish was spoken in the home (in seven cases, the language situation is unknown). The most common languages other than Swedish were Arabic (4), German (4), English (3), and Spanish (2). Other languages were Amharic, Dari, Greek, Lithuanian, Portuguese, Punjabi, Russian, Somali, and Tigrinya, and in one case parents reported that both Turkish and Kurdish were spoken in the home. The socioeconomic background of the participants was predominantly high: nearly 80 percent lived in two-parent households and nearly 70 percent had at least one parent with university-level education. A quarter of the sample had at least one parent with a yearly income above 500,000 SEK. (The Swedish average income 2016 was 300,000 SEK; SCB, 2018). Children spent on average 39 hours/week at preschool (range $25-51$ hours, $\mathrm{SD}=5$ ) and mean age at preschool start was 20 months (range $12-64$ months, $S D=0.11$ years).

\section{Materials}

The following is a description of the tasks/tests administered in the first and in the second round of testing and the measures extracted for analysis, which were all 
Table 1. Sample characteristics

\begin{tabular}{lccc}
\hline Full sample & Boys & Girls & Total \\
\hline Participants & 24 & 23 & $\mathbf{4 7}$ \\
\hline Monolingual Swedish & 9 & 8 & $\mathbf{1 7}$ \\
\hline Additional language/s in the home & 12 & 11 & $\mathbf{2 3}$ \\
\hline NAs & 3 & 4 & $\mathbf{7}$ \\
\hline Two-parent household & 19 & 18 & $\mathbf{3 7}$ \\
\hline Single-parent household & 1 & 2 & $\mathbf{3}$ \\
\hline Shared residency & 2 & 0 & $\mathbf{2}$ \\
\hline NAs & 2 & 3 & $\mathbf{5}$ \\
\hline$\geq 1$ parent with university level education & 16 & 16 & $\mathbf{3 2}$ \\
\hline No parent with university level education & 6 & 4 & $\mathbf{1 0}$ \\
\hline NAs & 2 & 3 & $\mathbf{5}$ \\
\hline$-\cdots$
\end{tabular}

based on assessment in testing round 2. Additionally, parental questionnaires concerning language development and demographic information are described.

\section{Language}

Initially, an informal story retell setup was used to elicit narrative data (Matthis, 1998). The task, in which children first watched and then were asked to retell the events in a short Winnie the Pooh video, yielded very sparse speech output and results thereof could not be analyzed. In testing round two, the task was replaced by the Bus Story Test (BST). BST involves retelling a short story aided by pictures in a booklet (Renfrew, 1995; Svensson \& Tuominen-Eriksson, 2002). The BST manual describes in detail how to calculate an information score that is said to reflect the child's ability to provide the events included in the original story and to relate the content of the story in the right order (Renfrew, 1995). To succeed, the child also needs adequate syntactic abilities and some knowledge about story structure (Westerveld \& Vidler, 2015), but the child is not required to retell the Bus Story verbatim to get a full score; the BST manual provides alternatives, based on comparative data for Swedish children aged 3.5-7.1 years. The following language measures were extracted from the narratives after transcription: (a) total number of words (tokens) as a measure of story length; (b) number of different words (types) as a measure of lexical diversity; (c) information score, calculated according to the BST manual; (d) morphosyntactic accuracy score, calculated as percent well-formed clauses; (e) syntactic complexity, defined as subordinate clauses per word token, thus controlling for variability in total story length; and (f) number of unified predicates per narrative as an additional measure of story length. A unified predicate is a unit containing a predicate that expresses a single situation, activity, state, or event (Berman, 1988), and is thus defined both on a syntactic level and on a semantic level. 
An unofficial translation (Ahlström \& Ljungman, 2011) of the Peabody Picture Vocabulary Test (PPVT-4; Dunn \& Dunn, 2007) was explored as a tool to assess receptive vocabulary, but the results thereof were not included in the study. Because there is no official Swedish PPVT translation or validation, it is highly unclear if the test provides a rising level of difficulty and furthermore the pictures are not culturally adapted for the Swedish context. ${ }^{3}$ No results from PPVT will be further mentioned, as recommended by anonymous reviewer.

The SCDI-III, the Swedish version of the McArthur-Bates communicative inventories (Berglund \& Eriksson, 2000; Eriksson, 2017) was administered once to parents during the data-collection phase. SCDI-III is intended for children up to age 4 but was at the time of data collection not validated. The subscales SCDIvocabulary and SCDI-morphology were included with the aim to contribute to a possible future validation procedure for children older than 4 years of age and results were treated with caution.

\section{Executive functions}

In the Dimensional Change Card Sort task (DCCS), the child is asked to sort pictures by a given sorting dimension (color or shape) into one of two locations, and then to switch to a new sorting rule. If performance is above threshold as decided by the application algorithm, the child is required to flexibly switch between these sorting rules. The task is suitable from 3 years of age according to test developers (Doebel \& Zelazo, 2015; Gershon et al., 2013; Weintraub et al., 2013).

The Flanker fish task mainly assesses the child's ability to suppress responses that are inappropriate in a particular context and it requires the child to indicate the direction of a central stimulus flanked by congruent or incongruent flankers. It is suitable from age 3 (Gershon et al., 2013; Rueda et al., 2004; Weintraub et al., 2013). DCCS and the Flanker fish task were administered using a tablet application, but the instructions were given by the examiner because there is no available Swedish-speaking tablet version. The child responds by touching the screen, no verbal response is required. Scoring is automatically logged using the application and is based on a combination of accuracy and reaction time for both Flanker and DCCS. Accuracy is considered first and if accuracy levels for the individual reach more than 80 percent, the reaction time score and accuracy score are combined (Slotkin et al., 2012).

The Head-Shoulders-Knees-and-Toes test (HSKT) reflects the child's ability to inhibit dominant responses of imitating the examiner and it is claimed to pose high demands on working memory and focused attention (Cameron Ponitz et al., 2008). HSKT consists of three sets with increasing level of difficulty. In the first set of trials, the child's task is to point at her toes when the examiner says and models "Point at your head" and vice versa. In the second set of trials, the child is instructed to point at his/her knees when the examiner says and models "Point at your shoulders" and vice versa, and in the third set of trials, instructions from set 1 and 2 are mixed. A score of 2 points is given for correct responses, 1 point is given when the child starts imitating the examiner but then self-corrects and 0 points is given when the child completes an erroneous response. 
Forward and Backward Digit Span (FDS and BDS) are intended to assess basic storage capacity in short-term memory and verbal working memory respectively (but see the preceding text for differing views on what constitutes working memory). The digits were sampled randomly from the sequence 1 to 9 and presented with increasing length of items, the child is awarded 2 points for repeating the digits after hearing the sequence once; 1 point if the child requests the examiner to repeat the sequence. The test was aborted after two errors in a row and raw scores were used for further analysis (Alloway, 2007; Bull et al., 2008; Gathercole et al., 1999).

\section{Communication}

To explore children's communicative skills in testing round 2, a novel rating scheme, developed by the second author, was applied. The protocol took ADOS rating scheme (Lord et al., 2000) as a vantage point and selected behaviors that are regarded essential for typical interactive behavior, and that can be clearly detected from video recordings of the test sessions. Gaze, gestures, body posture, fluency and prosody, the ability to follow instructions, turn-taking, and curiosity/initiative were thus rated as predominantly present or absent. As different test tasks may place different demands on a child, 2 minutes each from three different test tasks were examined for each individual, leading to 6 minutes in total per child: (a) the introduction to the assessment situation and the beginning of DCCS where the examiner and the child usually turned to face each other although seated side by side; (b) BST, appearing in the middle of the assessment session; and (c) HSKT that ended the session and where the test leader and child were standing up, facing each other. Each rated situation could thus receive a maximum of 7 points and the total communication score was calculated as proportion of adequate communicative behavior over all assessed situations.

\section{Demographic information}

In addition, parents filled out a questionnaire regarding background information such as family situation, parental income and educational level, languages spoken in the home, child age at preschool enrollment, and current amount of preschool attendance. The questionnaires were administered to parents before the first testing round and were returned in prepaid envelopes.

\section{Procedure}

Testing took place in a quiet room at the participants' preschool and was conducted by researchers. As previously mentioned, we carried out two testing rounds with a 6 -week interval, allowing for adjustments between round 1 and 2, which was important because many of the test tasks and materials had not previously been used with Swedish children. The first round of testing, in which the tasks were presented in a randomized, counterbalanced order, revealed a need for some adaptations to the examiner protocol for instructions and feedback to be appropriate for the Swedish context. Evaluations from the first testing round also indicated a need for adjustments to the procedure to ensure better time management and sufficient variation for participants. Furthermore, some of the assessments were deemed 
unsuitable for further analysis. As mentioned in the preceding text, the original story retell task yielded insufficient data and the aforementioned language measures could not be extracted. For the DCCS, the translation of instructions to the child was discussed with the test developers; the wording was kept as close to the original as possible and the crucial concepts color and shape were thus translated to Swedish färg and form. However, when presenting children with the task, the concept shape did not seem to be familiar to the children. The translation was subsequently changed in the second round of testing to sak; the Swedish word for thing. The HSKT had six items per condition in the first round of testing, which proved lengthy for the child and difficult to score for the examiner. It was changed to four items per condition in test round 2 and any comparisons between test round 1 and 2 are thus precluded.

All results reported are, as previously mentioned, based on the second round of testing, during which the tasks were presented in a fixed order to provide variation and to control session duration, as suggested by Traverso et al. (2015). Testing consisted of two sessions, to keep the testing to approximately 30 minutes and to avoid fatigue. The order for session 1 was DCCS, Bus Story, and HSKT and for session 2 The Fish Flanker Task and finally the digit span tasks. The assessment sessions were videotaped with a Canon XA 10 video camera audio recorded with Sennheiser MKE 2 lapel microphones.

ELAN software (ELAN, 2016; Wittenburg et al., 2006) was used to orthographically transcribe children's narratives and all transcriptions were done by the first author. Word tokens and types were extracted using ELAN and the other language measures were extracted manually on the basis of the transcripts.

\section{Inter- and Intrarater Reliability}

For interrater agreement, a random sample of six narratives were retranscribed by the second author and rescored. Information scores had a maximum difference of two points when comparing the transcriptions whereas for syntactic complexity and text length the scoring was identical. For intrarater agreement, the first author also completed a second information scoring round for all participants. The different scoring versions were compared in data analysis and did not lead to any differences in the results. A random sample of five video-recordings were rated on communication by a research assistant and compared with the original ratings of the second author. The second rater gave somewhat lower communication scores on average, but the difference between ratings was not significant and did not lead to any differences in results.

\section{Analytic Strategy}

Statistical analysis was performed in R (Version 3.6.1; R Core Team, 2019). To examine RQ 1, correlations between language, EF, and communication measures, Spearman's rank-order correlations were calculated because the sample was small and the data included potential outliers. For EF, in addition to examining potential correlations to language and communication for all separate EF measures, an EF composite score was created by summing z-transformed scores on the EF tests 
because different EF tasks possibly tap into more than one core EF component and also because EF could be regarded as a unitary structure in young children. For comparisons between groups, such as monolingual versus bi-/multilingual children, or girls versus boys, Welch's t-test, which does not assume equal variance, was used.

To examine RQ 2, multiple linear regression models were fitted with the $\mathrm{lm}$ and step functions in the R Stats Package (ibid.). The $\mathrm{lm}$ function is used to fit linear models and the step function is a stepwise algorithm that sequentially computes the log ratios that explain maximum variance in the data at hand. We investigated eventual main effects of the following independent variables: child age, sex, presence of additional languages in the home, family SES, age at preschool enrollment, and amount of time per week currently spent at preschool. Additionally, an eventual interaction effect of bi-/multilingualism and SES was investigated, based on the knowledge that children with at least one foreign-born parent are at higher risk of poverty than children with Swedish-born parents (SCB, 2017).

Gender was dummy coded, whereas for SES, a 10-grade scale was estimated on the basis of both parents' annual income and education level. A composite score was calculated for each parent and the mean score of both parents was used in regression models (see also Gerholm et al., 2018; Gerholm et al., 2019):

$$
\text { SES score }=((\text { Income score }+ \text { Education score }) \times 2)-4
$$

To rule out potential problems with multicollinearity and to potentially inform the choice of interaction terms in regression models, each independent variable was regressed on each of the other independent variables. As a rule of thumb, $R^{2}$ above 0.75 is a potential problem with regard to multicollinearity (Stat Trek, n.d.). No model had a coefficient of multiple determination above 0.07 .

The direction of the stepwise regression was bidirectional, and maximum number of steps was set to a default value, thus returning all relevant models. Model comparison was conducted by applying Akaike information criterion (AIC; e.g., Akaike, 1973), which is based on information theory and can be interpreted without the aid of significance levels. AIC estimates the quality of each fitted model, relative to the other models, using the full regression model as baseline. In addition to AIC values, AIC differences, and AIC weights are reported because this is the recommended procedure (see e.g., Burnham \& Anderson, 2002). AIC weights can be interpreted as conditional probabilities for each model. The preferred model was thus chosen based on the size of the AIC, that is, models with the lowest AIC values were preferred.

\section{Results}

The results section is organized as follows: First, descriptive results related to RQ 1 are presented (relationships between measures of language, EF, and communication). Finally, RQ 2 (relationships between language/EF and demographic variables) is addressed by fitting and comparing multiple regression models. 


\section{RQ 1. Relationships between Language, Executive Functions and Communication}

All analyses are, as previously mentioned, based on scores obtained from testing round 2 .

\section{Language}

Descriptive statistics of language, EF, and communication measures, including mean values, ranges, and standard deviations are displayed in Table 2. There was substantial variability in language performance; however, there were no significant differences between monolingual and bi-/multilingual children on any of the language measures. All children were thus treated as one group when investigating correlations between measures (bi-/multilingualism was however included as a predictor in regression models, see next section on results regarding RQ2). The mean number of word tokens was $130(S D=49)$ and the mean number of word types was $68(S D=23)$. On average, children received an information score of $20(S D=10)$ out of the maximum 54 points that can be achieved according to the BST manual. No children produced completely well-formed utterances throughout the narrative, the mean morphosyntactic accuracy score was 54 percent $(S D=20)$ and syntactic complexity was generally quite low-seven of the participants did not produce any subordinate clauses at all.

Turning to correlations between language measures (Table 3), word tokens did not correlate with any other measure. The other languages measures extracted from the narrative showed significant correlations that in some cases were very strong. For instance, word types and unified predicates had a Spearman correlation coefficient of 0.80 , and syntactic complexity correlated with unified predicates at $\rho=0.72$. SCDI-words correlated with information score and with syntactic complexity but not with word types/lexical diversity, whereas SCDI-morphology did not correlate with any other language measure.

The following language measures were selected for further analysis: word types, representing lexical diversity; percent well-formed utterances, representing morphosyntactic accuracy; and unified predicates, representing story length but also to some extent content of the story. The selection was based on the conceptual idea that these measures capture different aspects of linguistic skills, but also that the data for these measures were roughly normally distributed (see also Figure 1). With regard to syntactic complexity and information score, correlations to EF measures will be mentioned in the following text, but no further analysis was conducted.

\section{EF}

For correlations and significance levels regarding EF measures, see Table 3. There was a positive correlation between DCCS and Flanker $(\rho=.60, p<.001)$ and between the two-digit span tasks $(\rho=.39, p=.01)$. HSKT correlated significantly with FDS $(\rho=.46, p=.003)$. BDS showed potential floor effects. An EF composite score, consisting of the sum of z-scores from DCCS, Flanker, and HSKT was calculated for further use in regression models. 
Table 2. Language, communication, and EF measures and comparisons between monolingual and bi-/multilingual children

\begin{tabular}{|c|c|c|c|c|}
\hline Measure: & $\begin{array}{l}\text { Monolingual } \\
\text { background }\end{array}$ & $\begin{array}{l}\text { Multilingual } \\
\text { background }\end{array}$ & $t$-value (df) & $p$-value \\
\hline \multicolumn{5}{|c|}{ Word tokens } \\
\hline Mean (SD): & $116.38(34.15)$ & $144.59(56.68)$ & $1.75(29.65)$ & .09 \\
\hline Range: & $38-163$ & $33-244$ & & \\
\hline \multicolumn{5}{|c|}{ Word types/Lexical diversity } \\
\hline Mean (SD): & $98.93(23.77)$ & $98.44(24.99)$ & $-0.06(30.42)$ & .95 \\
\hline Range: & $25-118$ & $28-129$ & & \\
\hline \multicolumn{5}{|c|}{ Information score } \\
\hline Mean (SD): & $23.65(11.19)$ & $17.42(9.59)$ & $-1.78(31.76)$ & .08 \\
\hline Range: & $7-44$ & $6-37$ & & \\
\hline \multicolumn{5}{|c|}{ Morphosyntactic accuracy } \\
\hline Mean (SD): & $62(15.56)$ & $50(21.18)$ & $-1.89(30.97)$ & .07 \\
\hline Range: & $33-86$ & $0-77$ & & \\
\hline \multicolumn{5}{|c|}{ Syntactic complexity } \\
\hline Mean (SD): & $0.03(0.03)$ & $0.02(0.01)$ & $-1.26(13.67)$ & .23 \\
\hline Range: & $0-0.11$ & $0-0.04$ & () & \\
\hline \multicolumn{5}{|c|}{ Unified predicates } \\
\hline Mean (SD): & $19.24(8.31)$ & $19.16(6.08)$ & $-0.03(29.06)$ & .98 \\
\hline Range: & $6-34$ & $8-31$ & & \\
\hline \multicolumn{5}{|l|}{ SCDI-words } \\
\hline Mean (SD): & $81.25(10.67)$ & $81.96(13.89)$ & $0.18(36.57)$ & .86 \\
\hline Range: & $58-98$ & $39-100$ & & \\
\hline \multicolumn{5}{|c|}{ SCDI-morphology } \\
\hline Mean (SD): & $8.18(1.67)$ & $8.17(1.70)$ & $-0.005(34.97)$ & 1 \\
\hline Range: & $5-10$ & $5-10$ & & \\
\hline \multicolumn{5}{|l|}{ DCCS } \\
\hline Mean (SD): & $4.18(2.98)$ & $4.06(2.72)$ & $-0.13(32.82)$ & .90 \\
\hline Range: & $0.25-7.87$ & $0.75-8.37$ & & \\
\hline \multicolumn{5}{|c|}{ Flanker task } \\
\hline Mean (SD): & $4.70(2.18)$ & $4.18(2.04)$ & $-0.76(33.34)$ & .45 \\
\hline Range: & $1.13-7.57$ & $0.25-7.69$ & & \\
\hline
\end{tabular}


Table 2. (Continued)

\begin{tabular}{|c|c|c|c|c|}
\hline Measure: & $\begin{array}{l}\text { Monolingual } \\
\text { background }\end{array}$ & $\begin{array}{l}\text { Multilingual } \\
\text { background }\end{array}$ & $t$-value (df) & $p$-value \\
\hline \multicolumn{5}{|l|}{ HSKT } \\
\hline Mean (SD): & $15.19(6.68)$ & $14.50(5.67)$ & $-0.32(29.65)$ & .75 \\
\hline Range: & $0-24$ & $0-20$ & & \\
\hline \multicolumn{5}{|l|}{ FDS } \\
\hline Mean (SD): & $5.59(1.18)$ & $5.11(1.08)$ & & \\
\hline Range: & $2-7$ & $3-7$ & $-1.25(32.32)$ & .22 \\
\hline \multicolumn{5}{|l|}{ BDS } \\
\hline Mean (SD): & $0.82(1.42)$ & $0.67(1.03)$ & $-0.37(29.02)$ & .71 \\
\hline Range: & $0-4$ & $0-3$ & & \\
\hline \multicolumn{5}{|c|}{ Communication } \\
\hline Mean (SD): & $88(10.80)$ & $86(13.95)$ & $-0.36(33.35)$ & .72 \\
\hline Range: & $57-100$ & $52-100$ & & \\
\hline
\end{tabular}

\section{Communication}

The communicative measure showed potential ceiling effects (Figure 2), but there was a mean difference in communication score when comparing girls $\left(\mathrm{M}_{\text {girls }}=0.92\right.$, $\mathrm{SD}=0.06)$ and boys $\left(M_{\mathrm{boys}}=0.84, \mathrm{SD}=0.14,95 \% \mathrm{CI}=-0.14-.0 .01, p=.02\right)$. Potential differences in communication rating in the three contexts were also examined: the introduction of DCCS, a section from the child's retelling of the Bus Story, and the last two minutes of HSKT. Ratings were significantly lower in the narrative test task $\left(M_{\mathrm{BST}}=5.66, S D=1.22\right)$ compared to HSKT $\left(M_{\mathrm{HSKT}}=6.65, S D=0.77\right.$, $t(67.833)=-4.394, p<.001)$ and lower during DCCS $\left(M_{\mathrm{DCCS}}=6.15 S D=1.03\right)$ than in $\operatorname{HSKT}(t(72.315)=2.465, p=.02)$. The mean difference between communication in DCCS and in the retell of the Bus Story was not significant $(p=.06)$.

\section{Language, EF, and communication}

When examining language measures in relation to separate EF measures (see Table 3), word types/lexical diversity correlated significantly with DCCS, Flanker, and FDS, and SCDI-words correlated with DCCS, Flanker, FDS, and BDS. Morphosyntactic accuracy correlated with Flanker and FDS, whereas information score correlated with DCCS and FDS. Syntactic complexity and number of unified predicates correlated with DCCS. SCDI-morphology showed significant associations with the Flanker task. There were no significant correlations between any language measure and HSKT. The EF composite measure was correlated to the selected language variables: EF correlated moderately but significantly with word types/lexical diversity $(\rho=0.34, p=.04)$ and with morphosyntactic accuracy 
Table 3. Spearman's rank-order correlations between language, EF, and communication measures

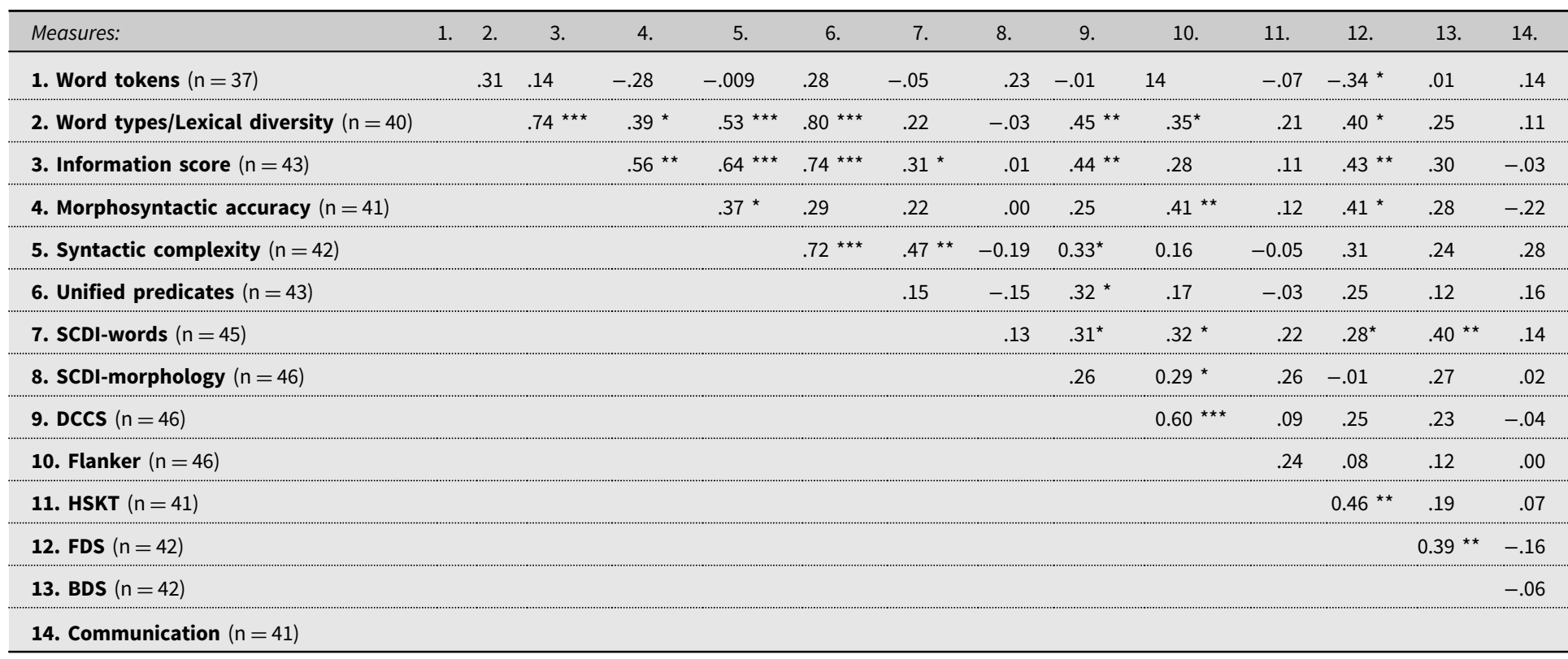



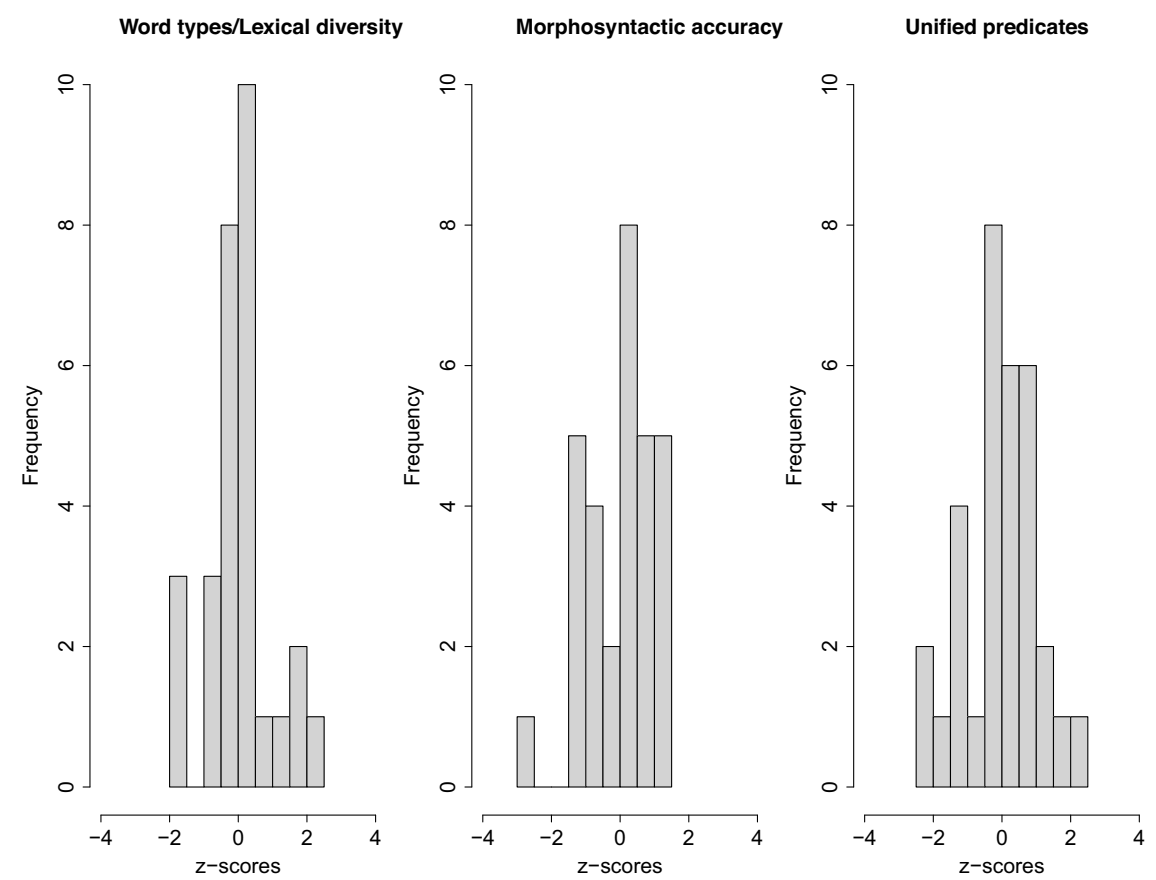

Figure 1. Scores for lexical diversity, morphosyntactic accuracy and unified predicates were roughly normally distributed.

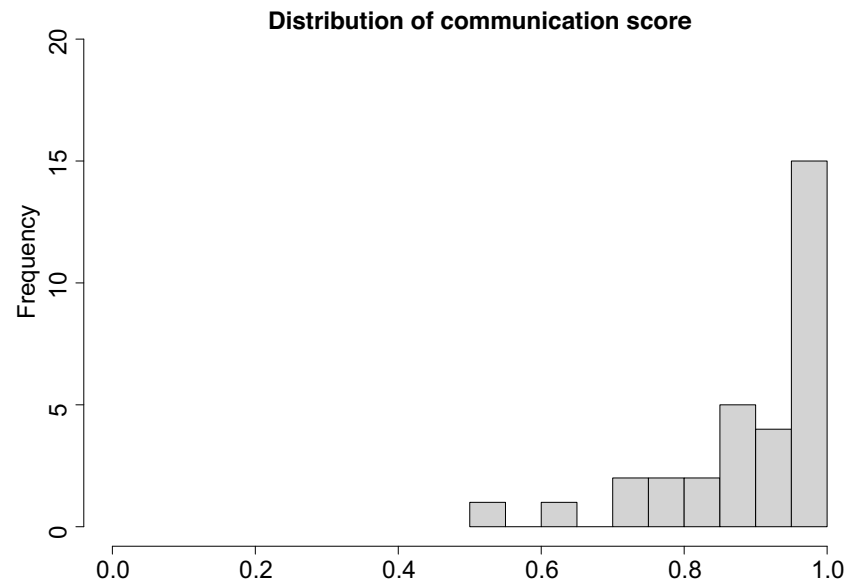

Figure 2. Distribution of communication score indicating a ceiling effect.

$(\rho=0.37, p=.02)$ but not with unified predicates $(\rho=0.17, p=.30)$. The communication ratings did not correlate with any language or EF measure.

To summarize, language measures correlated more with one another than with EF measures. Exceptions were SCDI-morphology, which correlated with the Flanker task but not with any language measures. Contrary to predictions, all EF measures 
did not correlate with one another. Language measures regarding lexicon/vocabulary (word types/lexical diversity; SCDI-words) correlated with more of the EF measures than language measures regarding morphosyntax. The communication rating did not correlate with language or $\mathrm{EF}$, but the mean communication score was significantly higher for girls than for boys.

\section{$R Q$ 2. Language and EF in Relation to Demographic Variables}

First, potential differences with regard to demographic variables between monolingual and bi-/multilingual children were examined with Welch's t-test: SES was significantly lower among children who had other/additional languages spoken in the home $\left(M_{\text {multi }}=5.95 ; S D=1.93\right)$ than in the monolingual Swedish group $\left(M_{\text {mono }}=7.56 ; S D=1.71\right)$. There were no significant differences between the monolingual group and the multilingual group with regard to age at preschool enrollment or current time/week at preschool.

Potential relationships between dependent variables (word types/lexical diversity, morphosyntactic accuracy, unified predicates, and EF composite score) and possible predictors (child age, sex, bi-/multilingualism, family SES, child age at preschool enrollment, child's current amount of time spent at preschool/week, and interaction between bi-/multilingualism and SES) were investigated. All dependent variables were z-transformed to facilitate interpretation of model estimates. The stepwise procedure previously described led to one or several reduced models for each dependent variable, which were then compared to the full model based on AIC values.

\section{Word types/lexical diversity}

The stepwise procedure led to a preferred model with age as the only predictor of lexical diversity. The preferred model was then compared to the full model, see Table 4 for AIC weights and adjusted $R^{2}$ and Figure 3 for residual versus fits plots. Age was a positive predictor of lexical diversity score $(B=0.05, C I=0.01-0.09$, $p=.013)$ and explained 18 percent of the variance in lexical diversity $(p=.01)$.

\section{Morphosyntactic accuracy}

A full model was compared to a simple model including only age at preschool enrollment as predictor of morphosyntactic accuracy. Explained variance was, however, very low and child age at preschool enrollment did not significantly predict morphosyntactic accuracy $(B=-0.02, C I=-0.05-0.005, p=0.1)$ (see also Table 5).

\section{Unified predicates}

A full model was compared to a simple model including only age as predictor of unified predicates score. Age in itself did not significantly predict unified predicates score $(B=0.04, C I=0.04-0.02, p=.07)$ and degree of explained variance was low. See Table 6 for model comparison.

EF

The stepwise procedure led to three models that were compared to the full model: (a) a simple model including only age; (b) an intermediate model including age and 
Table 4. Model comparison for word types/lexical diversity

\begin{tabular}{lcccccc}
\hline & $\begin{array}{c}\text { Adj. } \\
\mathrm{R}^{2}\end{array}$ & $\begin{array}{c}\text { Residual } \\
\text { deviance }\end{array}$ & $\begin{array}{c}\text { Residual } \\
\text { df }\end{array}$ & $\begin{array}{c}\Delta_{i} \\
\text { (AIC) }\end{array}$ & $\begin{array}{c}W_{i} \\
\text { (AIC) }\end{array}$ \\
\hline Full Lexical diversity model & 0.03 & 21.2 & 22 & 89.3 & 8.7 & 0.01 \\
\hline $\begin{array}{l}\text { Preferred Lexical diversity model } \\
\text { (age) }\end{array}$ & 0.18 & 22.2 & 27 & 80.6 & 0 & 0.99 \\
\hline
\end{tabular}

Note: AIC differences $\left(\Delta_{\mathrm{i}}(\mathrm{AIC})\right.$ ) allow a quick ranking of candidate models and are useful in calculating AIC weights ( $\mathrm{w}_{\mathrm{i}}$ (AIC)), which in turn indicate the relative likelihood of the model given the data and the set of models. See also Burnham and Anderson (2002).
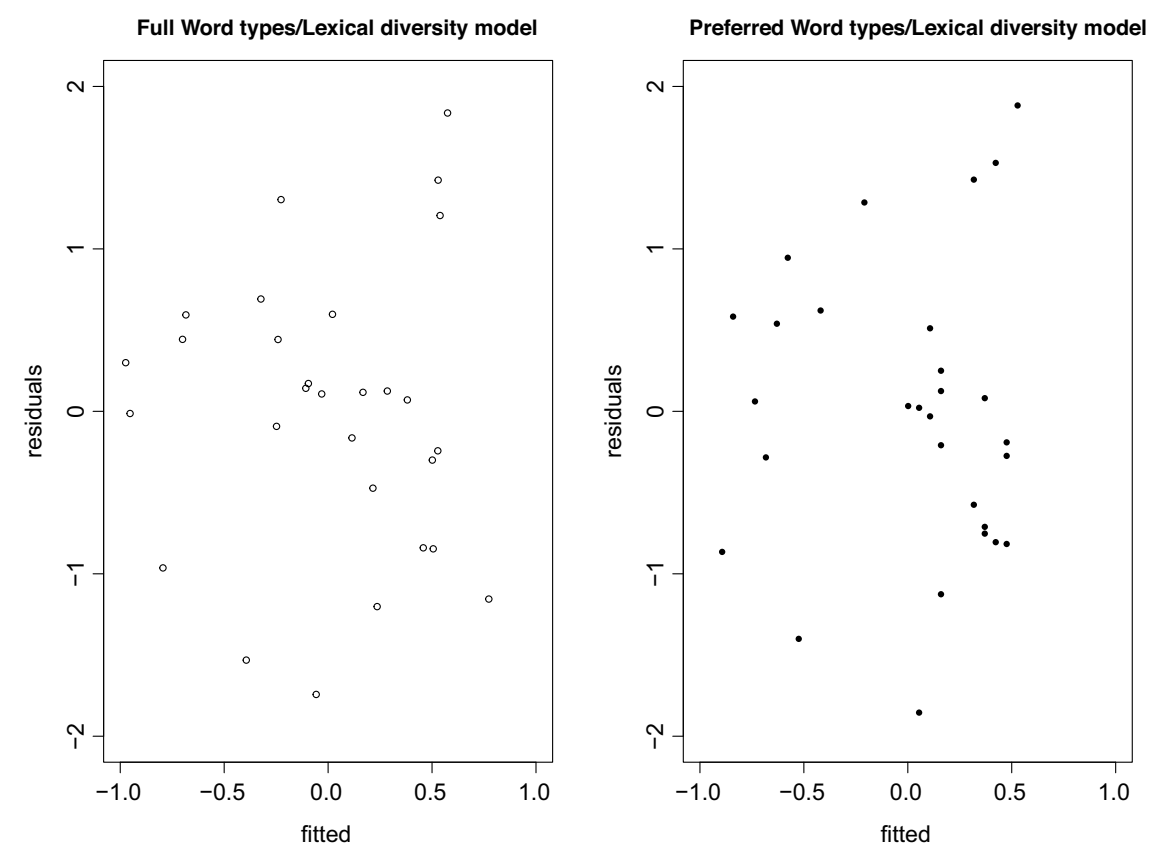

Figure 3 Residuals versus fits plots for the full lexical diversity model and the preferred model, the latter with age as the only predictor of lexical diversity.

sex; and (c) a preferred model based on its AIC values and including age, sex, and time/week at preschool as predictors of EF composite score (see also Table 7 and Figure 4). The preferred model explained 24 percent of EF score variance $(p=.02)$. Male sex was a significant positive predictor but the confidence interval was rather large $(B=1.12, C I=0.04-2.19, p=.04)$.

\section{Discussion}

The current pilot study is one of the first to examine relationships between language skills and executive functions in a sample of mono- and bi-/multilingual Swedish preschoolers. In line with our predictions, language measures correlated more with one another than with EF measures. A forward digit span task correlated more with 
Table 5. Model comparison for morphosyntactic accuracy

\begin{tabular}{lcccccc}
\hline & $\begin{array}{c}\text { Adj. } \\
\mathrm{R}^{2}\end{array}$ & $\begin{array}{c}\text { Residual } \\
\text { deviance }\end{array}$ & $\begin{array}{c}\text { Residual } \\
\text { df }\end{array}$ & $\begin{array}{c}\Delta_{i} \\
\text { AIC }\end{array}$ & $\begin{array}{c}w_{i} \\
\text { (AIC) }\end{array}$ \\
\hline (AIC)
\end{tabular}

Note: $\Delta_{\mathrm{i}}(\mathrm{AIC})=$ AIC differences; $\mathrm{w}_{\mathrm{i}}(\mathrm{AIC})=$ AIC weights. The preferred model is underlined; included predictor within parentheses.

Table 6. Model comparison for unified predicates

\begin{tabular}{ccccccc}
\hline & $\begin{array}{c}\text { Adj. } \\
\mathrm{R}^{2}\end{array}$ & $\begin{array}{c}\text { Residual } \\
\text { deviance }\end{array}$ & $\begin{array}{c}\text { Residual } \\
\text { df }\end{array}$ & AIC & $\begin{array}{c}\Delta_{i} \\
\text { (AIC) }\end{array}$ & $\begin{array}{c}\mathrm{w}_{\mathrm{i}} \\
\text { (AIC) }\end{array}$ \\
\hline Full Unified predicates model & -0.04 & 26 & 25 & 100.0 & 8 & 0.02 \\
\hline $\begin{array}{l}\text { Preferred Unified predicates } \\
\text { model (age) }\end{array}$ & 0.08 & 27.7 & 30 & 92.2 & 0 & 0.98 \\
\hline
\end{tabular}

Note: $\Delta_{\mathrm{i}}(\mathrm{AIC})=$ AIC differences; $\mathrm{w}_{\mathrm{i}}(\mathrm{AIC})=\mathrm{AIC}$ weights. The preferred model is underlined; included predictor within parentheses.

Table 7. Model comparison for EF composite score

\begin{tabular}{|c|c|c|c|c|c|c|}
\hline & $\begin{array}{l}\text { Adj. } \\
\mathrm{R}^{2}\end{array}$ & $\begin{array}{l}\text { Residual } \\
\text { deviance }\end{array}$ & $\begin{array}{l}\text { Residual } \\
\text { df }\end{array}$ & $\mathrm{AIC}$ & $\begin{array}{c}\Delta_{\mathrm{i}} \\
(\mathrm{AIC})\end{array}$ & $\begin{array}{c}w_{\mathrm{i}} \\
(\mathrm{AIC})\end{array}$ \\
\hline Full EF model & 0.19 & 47.0 & 23 & 115.0 & 4.3 & 0.04 \\
\hline Simple model (age) & 0.12 & 62.1 & 28 & 113.0 & 2.7 & 0.13 \\
\hline $\begin{array}{l}\text { Intermediate model (age and } \\
\text { sex) }\end{array}$ & 0.20 & 54.6 & 27 & 111.0 & 0.8 & 0.33 \\
\hline$\frac{\text { Preferred EF model }}{\text { (age, sex and time/week) }}$ & 0.24 & 49.7 & 26 & 110.0 & 0 & 0.5 \\
\hline
\end{tabular}

Note: $\Delta_{\mathrm{i}}(\mathrm{AIC})=$ AIC differences; $\mathrm{w}_{\mathrm{i}}(\mathrm{AIC})=$ AIC weights. The preferred model is underlined; included predictors within parentheses.

language measures than with EF measures. Age was to a large extent a significant positive predictor of language and EF performance. In the current data, male sex was a positive predictor of EF performance, whereas there was a slight female advantage with regard to ratings of communication skills. SES as an aggregate measure of parental income and educational level did not explain variance in language nor EF. Results regarding potential predictive value of age at preschool start and time/week on language and $\mathrm{EF}$ were inconclusive.

Our first research question regarded correlations between measures of language extracted from children's narratives, parent-rated vocabulary/morphology, measures of EF, and communication ratings. The hypothesis that all language measures would correlate more with one another than with $\mathrm{EF}$ and vice versa could not be confirmed because SCDI-morphology showed no significant correlations with other language measures but correlated significantly with the Flanker task. FDS correlated 

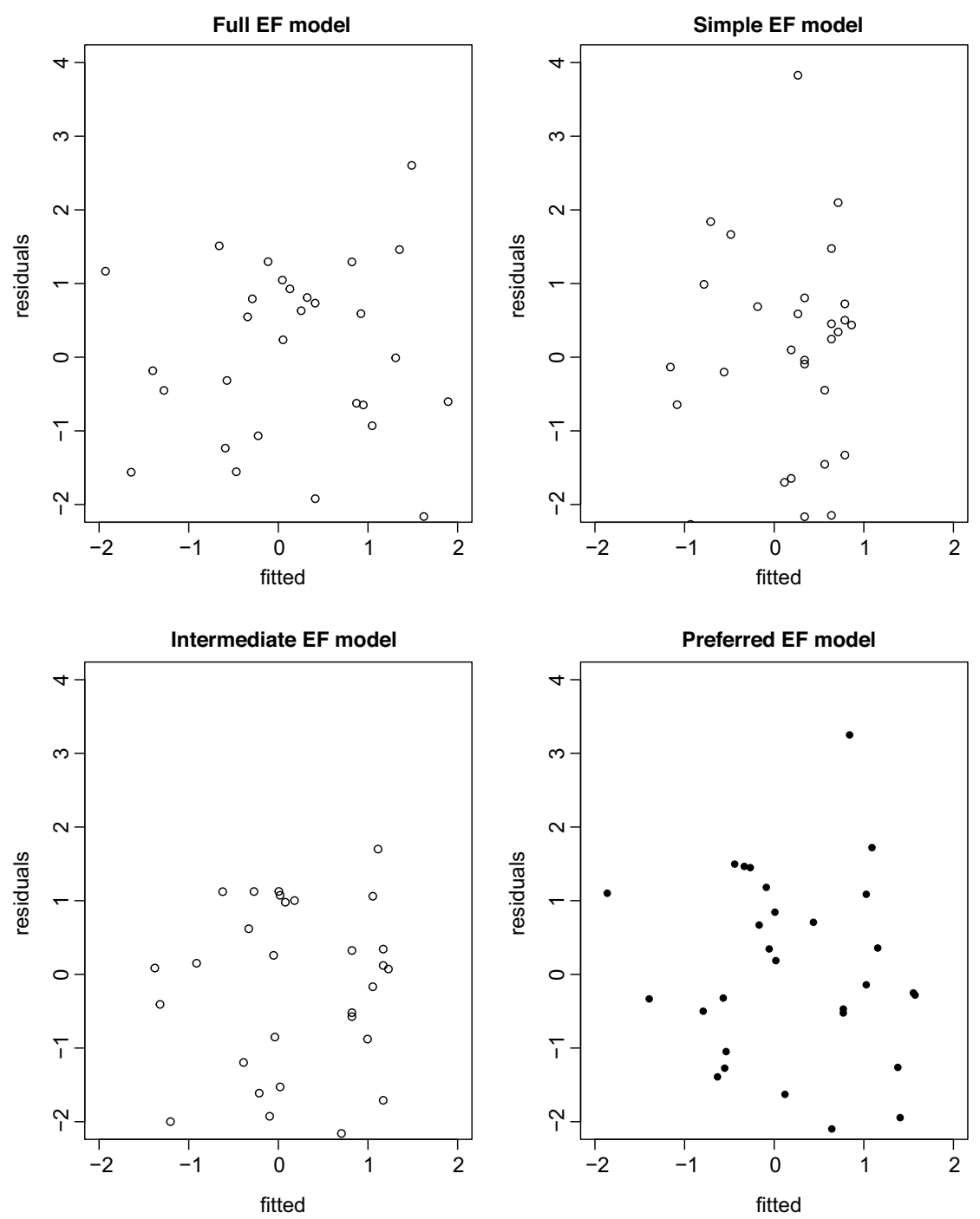

Figure 4. Residuals versus fits plots for the four different EF models. The preferred model included age, sex and time/week at preschool as predictors. The only predictor of lexical diversity.

with most language measures but to a lesser extent with EF measures, reinforcing the view that forward digit span tasks should be regarded as measures of phonological short-term memory rather than working memory (e.g., Tulsky et al., 2013), in line with the claim that working memory is assessed by more complex tasks that demand maintenance and manipulation of the material (see also Aben et al., 2012; and Vissers et al., 2015). The expectation that all EF measures would be significantly correlated could not be confirmed, thus our results do not consolidate the assumption that EF is a unitary construct during childhood (Fuhs \& Day, 2011; Wiebe et al., 2008). A conceptual problem with EF tests in general is that they 
are more opaque than language measures because they measure more abstract constructs or underlying latent variables.

We also predicted significant correlations between language and EF measures, which was the case, but the results also revealed some differentiation: the word types/lexical diversity measure and SCDI-vocabulary correlated with several EF tasks, in line with previous studies that have found relationships between aspects of vocabulary and EF (e.g., Fuhs \& Day, 2011; Weiland et al., 2014). Syntactic complexity correlated with DCCS, a measure of cognitive flexibility, which could be interpreted in the light of Zelazo's (2015) suggestion that language can aid EF performance or that EF is verbally mediated, perhaps specifically because the ability to formulate complex embedded rules may facilitate cognitive flexibility in particular (see however Kirkham and Diamond [2003] for an alternative explanation). Measures related to grammar, namely syntactic complexity, morphosyntactic accuracy, and SCDI-morphology correlated with the Flanker task, which assesses inhibitory control. Previous work has shown that inhibitory control predicts grammar skills in 5-year-olds (Ibbotson \& Kearnell-White, 2015). In developmental language disorder (DLD; formerly "specific language impairment" [SLI]), morphosyntactic difficulties are regarded as a cardinal symptom, and children with DLD have been shown to also have difficulties with inhibition (e.g., Marton et al., 2007). Furthermore, studies have shown that patients with aphasia also have selectively impaired inhibitory mechanisms (e.g., Peristeri et al., 2011; Wiener et al., 2004). There were no significant correlations between any language measures and HSKT, which is somewhat surprising because HSKT requires the child both to follow quite complex verbal instructions and to keep rules in mind. It may be that the current narrative language measures do not sufficiently capture aspects of language comprehension. Alternative interpretations could be that the playful setting of HSKT in some way eases the burden of grasping the instruction. Children's communication skills were rated higher in the HSKT situation than in the other two assessed situations and it is feasible that small contextual differences or perceived task demands may affect children's EF performance. It could also be the case that HSKT is a purer EF measure than DCCS and Flanker. In summary, the correlational patterns between language and EF measures in the current pilot study indicate that there may be specific links between for instance morphosyntax and inhibition, but that the language-EF relationship may also be highly dependent on the type of task and the specific context. It could be argued that examining narrative skills in conjunction with EF increases the inherent task impurity problem because aspects of EF are required in story retell as well as story generation (e.g., Friend \& Bates, 2014; Gabig, 2008). However, if we are attempting to understand the interplay between cognitive abilities and language use, using narrative assessment is probably more informative than experimental, highly specific, and decontextualized language tasks.

Some measures employed in the current pilot study were problematic: We explored the potential use of SCDI-III for children over 4 years of age, but there were indications of ceiling effects for SCDI-morphology, which makes further use of the morphology scale above age 4 questionable. SCDI-vocabulary shows some promise, but further work is needed to find out whether the instrument is reliable and valid beyond 4 years of age. BDS had floor effects and use of BDS as a test of working memory for 4- to 6-year-olds can be questioned. There is a need for a 
consistent and child-friendly auditory working memory test instrument, preferably not dependent upon language skills. Quasi-universal nonword repetition tasks (NWRT), in which the participant repeats a series of nonwords of differing syllable length and phonological complexity, are less linguistically biased than memory tests based on real words. However, such tasks are described as a measure of phonological short-term memory rather than, or in addition to, a measure of working memory (e.g., Baddeley, 2001). Furthermore, NWRT are employed to identify disorders of language and literacy (e.g., Coady \& Evans, 2008), so there seems to be task impurity both with regard to short-term versus working memory and with regard to EF and language. A novel communication rating scheme was explored but results did not show significant relationships to language or EF and there were indications of potential ceiling effects. The communication ratings should thus be treated with caution, but even so, they reveal significant variability in children's communicative behavior when comparing different aspects of the assessment situation, suggesting that rather small contextual differences can impact the way children communicate with the interlocutor.

Our second research question concerned relationships between background factors (age, sex, bi-/multilingualism, SES, and aspects of preschool attendance) and language and/or EF. As predicted, age did to some extent predict language and $\mathrm{EF}$ performance. However, the predictive value of age was rather modest, in line with previous results regarding language development (e.g., McKean et al., 2017) as well as cognitive development (e.g., Eriksen et al., 2013), indicating that although age significantly predicted outcomes, the amount of explained variance is low. Potential differences between and variability in language and EF skills within age groups should be further explored in a larger sample.

The current study did not find support for differences between girls and boys in language performance. However, the communication ratings revealed a significantly higher mean score for girls compared to boys, and future studies could attempt at identifying more fine-grained measures of interaction that can capture variation in communicative behavior in typically developing children. Male sex was a positive predictor of EF in the current study; it should, however, be pointed out that a recent review paper reached the conclusion that sex-related differences in EF are subtle or nonexisting (Grissom \& Reyes, 2019). The authors suggest that small variations in task design may be one possible reason behind the fact that earlier work has reached different conclusions regarding sex differences in EF (ibid.), which highlights the need for reliable and well-designed EF tasks with solid construct validity.

The current sample reflects the Swedish multicultural society and included a large proportion of children from bi- or multilingual family backgrounds. There were no significant differences between monolingual and bi-/multilingual children for any of the language measures. Previous work showed that narrative assessment seems less biased with regard to aspects of narrative macrostructure compared to diagnostic instruments with monolingual norms only (e.g., Gagarina et al., 2015; Heilmann et al., 2010), and the current study indicates that assessment of narrative microstructure, such as measures of lexical diversity and syntactic complexity, may also be less biased for bi- or multilingual children compared to standardized language tests. Neither were there any differences in EF scores when comparing monolingual and bilingual children. Previous work claiming a cognitive advantage for bilinguals, for instance with regard to EF, has lately been questioned: Studies have 
been criticized for failing to match monolingual and bilingual groups on demographic factors such as SES (e.g., Duñabeitia et al., 2014; Paap et al., 2015). Although our pilot study is small, the results are congruent with a view that bi-/multilingualism per se is neither advantageous nor disadvantageous with regard to EF. Additional aspects such as family SES and possible effects of the language combination, and input, of the different languages need consideration, which has also been pointed out by Bohnacker et al. (2016) and Lindgren (2018) specifically for the Swedish context.

The current sample was skewed toward higher SES. We treated SES as a composite measure, comprising information on both parents' income and education, which is similar to many previous studies (see e.g., Noble et al., 2007), but we did not find any effects of SES on language or EF. One reason to use a composite SES measure was to reduce the number of predictor variables in regression models. However, such a procedure may obscure specific effects of income and education, respectively. Longitudinal studies have indicated that family and environmental factors are not very accurate predictors of later language ability (e.g., McKean et al., 2017), but with regard to cognitive development, parental education have been recommended as a mandatory covariate in statistical modeling (e.g., Eriksen et al., 2013).

With regard to associations between aspects of preschool attendance, language, and EF, no specific hypotheses were made because this matter is largely underinvestigated in the Swedish context. We did not find any significant effects of child age at preschool enrollment or weekly attendance on any language or EF measures.

\section{Limitations and Future Directions}

A general limitation of most pilot studies is the small sample size. From a methodological point of view, a multiple regression approach in a small sample as the current one can be questioned because the sample size should preferably exceed the number of independent variables by at least 50 (Harris, 2001). Instead of focusing only on significance levels, we opted for an information-theoretical approach to evaluate regression models and the results of the current study are not generalizable but can guide hypotheses for future research. There may be complex relationships between aspects of family SES, preschool attendance, and the development of language and EF skills, which need further attention in studies including a larger and more SES-diverse sample. With regard to investigating potential influences of preschool attendance on language and EF, it could be favorable to use a multilevel modeling approach, thereby accommodating the clustered structure of the data. Swedish preschools are organized in classrooms or units that may be of different group sizes, and of different age compositions, ranging from completely mixed groups with children from age 1 to age 5 in the same classroom, to age-homogeneous units with only 5 year olds. A multilevel modeling approach would be able to account for random effects both at the individual level, the classroom/unit level, and the preschool level (see also Gerholm et al., 2018; Gerholm et al., 2019).

\section{Language}

Because a child's language use is affected by the specific linguistic context (e.g., Berman, 2004), it is important to stress that we are assessing narrative language in a story retell task and the results should be interpreted in that contextual light. 
In future studies, the Bus Story Test could be complemented by a task in which children not only retell a story but generate their own narrative, not least because the importance of using different narrative elicitation methods has been pointed out, in particular with regard to bilingual children (see e.g., Kunnari et al., 2016). The LITMUS-MAIN provides means to elicit children's narratives in various tasks; it has been used in several languages and attempts have been made to ensure that the material is suitable for children from diverse linguistic and cultural backgrounds (Gagarina et al., 2015). With regard to instruments that assess more specific aspects of language, there is a need for reliable tests of receptive and productive vocabulary in Swedish-speaking children. A Swedish master's thesis, although not available at the time of data collection for the current study, has developed a translation and adaptation of PPVT that seems to achieve a rising level of difficulty (Karner \& Mattsin, 2017), and another promising approach is to use crosslinguistic tasks/CLT (e.g., Haman et al., 2017), but in both cases Swedish norms are lacking.

\section{EF}

As for the EF measures, DCCS and Flanker shows links to aspects of language, in line with previous studies. The tasks thus seem promising for further use in the Swedish context; however, a Swedish standardization of the DCCS and Flanker tasks should be undertaken. HSKT appears intuitively as an ecological valid measure compared to traditional table-top tasks, more resembling real-life situations, and, as opposed to the other EF measures employed in the current study, not correlated to the language measures, suggesting that it may be a purer EF measure. To disentangle the relation between potentially different EF skills in the current age group, further work is needed, for instance by administering a wider array of carefully designed EF tasks to a larger sample of children. Additionally, separating participants into narrow age bands has been suggested to reveal separation into the core EF components even in 3- to 4 -year-old children (Howard et al., 2015). Data could be analyzed with structural equation modeling methods, similar to the seminal work of Miyake and colleagues for adults (2000) and work investigating the nature of EF in school-aged children (e.g., Wu et al., 2011).

\section{Bi-/multilingualism}

Multilingual children should preferably be assessed in all their languages, which is challenging given that 15 different languages other than Swedish were spoken in the homes in the current sample of 47 children. Future studies should collect data on children's use of and exposure to the languages as well as information about the parents' background, time spent in the country, and so forth. Considering Lindgren's (2018) conclusion that it is not meaningful to compare all bilingual children with all monolingual children when investigating narrative competence, future studies should also attempt at recruiting sufficiently large subgroups of children who share the same linguistic and cultural background.

\section{SES}

More information regarding SES would be desirable. At the same time, detailed questions regarding income and occupational status may be perceived as sensitive 
and the risk of missing data may increase. The parental questionnaire used in the current pilot study was gender-neutral not to discriminate against nonbinary parents or families with same-sex parents. However, this precludes specific conclusions about mothers and fathers in relation to SES-related measures and turned out a shortcoming in the present study. Another potential problem related to SES was that the variation in the current sample was smaller than expected given the general income and educational level in the area. It is feasible that families from lower-SES backgrounds chose not to participate in the study to a higher degree than higher-SES families.

\section{Preschool attendance}

Given the high proportion of children attending preschool in Sweden and the general lack of studies investigating children's outcomes in relation to preschool-related factors, the possible impact of preschool attendance and specific pedagogical methods or interventions on Swedish children's language and EF development should be further investigated, also in longitudinal studies tracking children's development during the preschool years (see also Gerholm et al., 2019).

\section{Conclusions}

Returning to the aims of the current study the following conclusions can be drawn: In line with previous studies, there were significant associations between language and EF in a sample of Swedish 4- to 6-year-olds, confirming a potential specific link between inhibition and aspects of morphosyntactic ability. Most EF tasks correlated with one or several language measures, except for HSKT, which supposedly requires both working memory and focused attention, and a tentative conclusion is that HSKT may be a purer and more ecologically valid EF task than others. Age was a significant predictor of some, but not all language and EF measures, reflecting the large variability in 4- to 6-year-old children. The pilot study included both monolingual and bi-/multilingual children, but there were no significant differences in language or EF performance and no unique predictive value of growing up with more than one language for any of the outcome measures. Aspects of parental SES did not show significant associations to language or EF. More fine-grained SES measures may be needed for future studies in the Swedish context and efforts should be made to recruit more SES-diverse samples. Potential links between individual children's language and EF skills and preschool attendance have to our knowledge not previously been systematically investigated in Sweden, where a vast majority of children attend preschool from 1-2 years of age until starting school at age 6 . Preschool factors need further investigation in future studies, considering the potentially complex interactions between family SES, language background, and preschool attendance. Potential effects of pedagogical approaches on Swedish children's language and EF development need further attention, and such an endeavor can shed further light on the cognitive mechanisms that support language development.

Acknowledgments. First and foremost, we wish to thank all participating children, parents, and preschool staff. We would also like to thank Dr. Sofia Frankenberg for her contributions in compiling the EF test battery and in performing the assessments, and Freya Eriksson for assisting in analysis of story transcripts. 


\section{Notes}

1. CELF-4 is not standardized for Swedish per se but for "Scandinavian" (Norwegian, Danish, and Swedish together), which constitutes a potential problem (thanks to anonymous reviewer for pointing this out).

2. Similar to the CELF-4, the norms for WPPSI-IV are Scandinavian, not Swedish.

3. Pearson Assessment were contacted to discuss our potential contribution to a validation process of PPVT-4, however, the company was not interested.

\section{References}

Abel, C., Nerren, J., \& Wilson, H. (2015). Leaping the language gap: Strategies for preschool and head start teachers. International Journal of Child Care and Education Policy, $\mathbf{1}, 1$.

Aben, B., Stapert, S., \& Blokland, A. (2012). About the distinction between working memory and shortterm memory. Frontiers in Psychology, 3, 301. doi: 10.3389/fpsyg.2012.00301

Adesope, O. O., Lavin, T., Thompson, T., \& Ungerleider, C. (2010). A systematic review and metaanalysis of the cognitive correlates of bilingualism. Review of Educational Research, 80, 207-245.

Ahlström, L., \& Ljungman, H. (2011). Åldersreferenser för Peabody Picture Vocabulary Test IV på svenska för flerspråkiga barn i skolår 4. Unpublished master thesis, Karolinska Institute, Stockholm, Sweden.

Akaike, H. (1973). Formation theory and an extension of the maximum likelihood principle In B. N. Petrov \& F. Csaki (Eds.), Second International Symposium on Information Theory (pp. 267-281). Akadémiai Kiado.

Alloway, T. P. (2007). Working memory, reading, and mathematical skills in children with developmental coordination disorder. Journal of Experimental Child Psychology, 96, 20-36.

Andersson, K., Hansson, K., Rosqvist, I., Lyberg Åhlander, V., Sahlén, B., \& Sandgren, O. (2019). The contribution of bilingualism, parental education, and school characteristics to performance on the clinical evaluation of language fundamentals: Fourth edition, Swedish. Frontiers in Psychology, 10[1586]. doi: 10. 3389/fpsyg.2019.01586

Baddeley A. D. (2001). Is working memory still working? The American Psychologist, 56, 851-864. https:// doi.org/10.1037/0003-066x.56.11.851

Barac, R., Moreno, S., \& Bialystok, E. (2016). Behavioral and electrophysiological differences in executive control between monolingual and bilingual children. Child Development, 87, 1277-1290. doi: 10.1111/ cdev. 12538

Barbu, S., Nardy, A., Chevrot, J.-P., Guellaï, B., Glas, L., Juhel, J., \& Lemasson, A. (2015). Sex differences in language across early childhood: Family socioeconomic status does not impact boys and girls equally. Frontiers in Psychology, 6, 1874. doi: 10.3389/fpsyg.2015.01874

Berglund, E., \& Eriksson, M. (2000). Reliability and content validity of a new instrument for assessment of communicative skills and language abilities in young Swedish children. Logopedics Phoniatrics Vocology, 25, 176-185. doi: 10.1080/140154300750067557

Berman, R. A. (1988). On the ability to relate events in narrative. Discourse Processes, 11, 469-497. doi: 10. 1080/01638538809544714

Berman, R. A. (2004). The role of context in developing narrative abilities. In S. Strömqvist \& L. T. Verhoeven (Eds.). Relating events in narrative. Vol. 2, Typological and contextual perspectives. Lawrence Erlbaum.

Berman, R. A., Slobin, D. I., \& Aksu-Koç, A. (1994). Relating events in narrative: A crosslinguistic developmental study. Lawrence Erlbaum Associates.

Bishop, D. V. M. (2003). Test for reception of grammar version 2 TROG-2 Manual. The Psychological Corporation.

Blain-Brière, B., Bouchard, C., \& Bigras, N. (2014). The role of executive functions in the pragmatic skills of children age 4-5. Frontiers in Psychology, 5, 240. doi: 10.3389/fpsyg.2014.00240

Blair, C., \& Raver, C. (2015). School readiness and self-regulation: A developmental psychobiological approach (Vol. 66). Annual Reviews Inc.

Bohnacker, U. (2016). Tell me a story in English or Swedish: Narrative production and comprehension in bilingual preschoolers and first graders. Applied Psycholinguistics, 37, 19-48. doi: 10.1017/ S0142716415000405 
Bohnacker, U., Lindgren, J., \& Öztekin, B. (2016). Turkish- and German-speaking bilingual 4-to-6-yearolds living in Sweden: Effects of age, SES and home language input on vocabulary production. Journal of Home Language Research, 1, 17-41.

Botting, N. (2002). Narrative as a tool for the assessment of linguistic and pragmatic impairments. Child Language Teaching and Therapy, 18, 1-21. doi: 10.1191/0265659002ct224oa

Botting, N., Morgan, G., Jones, A., Marshall, C., Denmark, T., \& Atkinson, J. (2017). Nonverbal executive function is mediated by language: A study of deaf and hearing children. Child Development, 88, 1689-1700. doi: $10.1111 /$ cdev.12659

Brocki, K. C., \& Bohlin, G. (2004). Executive functions in children aged 6 to 13: A dimensional and developmental study. Developmental Neuropsychology, 26, 571-593. doi: 10.1207/s15326942dn2602_3

Brocki, K. C., Eninger, L., Thorell, L. B., \& Bohlin, G. (2010). Interrelations between executive function and symptoms of hyperactivity/impulsivity and inattention in preschoolers: A two year longitudinal study. Journal of Abnormal Child Psychology, 38, 163-171. doi: 10.1007/s10802-009-9354-9

Brown, T. T., \& Jernigan, T. L. (2012). Brain development during the preschool years. Neuropsychology Review, 1-21. doi: 10.1007/s11065-012-9214-1

Bull, R., Espy, K. A., \& Wiebe, S. A. (2008). Short-term memory, working memory, and executive functioning in preschoolers: Longitudinal predictors of mathematical achievement at age 7 years. Developmental Neuropsychology, 33, 205.

Burger, K. (2010). How does early childhood care and education affect cognitive development? An international review of the effects of early interventions for children from different social backgrounds. Early Childhood Research Quarterly, 25, 140-165. https://doi.org/10.1016/j.ecresq.2009.11.001

Burnham, K. P., \& Anderson, D. R. (2002). Model selection and multimodel inference: A practical information-theoretic approach. Springer.

Calvo, A., \& Bialystok, E. (2014). Independent effects of bilingualism and socioeconomic status on language ability and executive functioning. Cognition, 130, 278-288. doi: 10.1016/j.cognition.2013.11.015

Cameron Ponitz, C. E., McClelland, M. M., Jewkes, A. M., Connor, C. M., Farris, C. L., \& Morrison, F. J. (2008). Touch your toes! Developing a direct measure of behavioral regulation in early childhood. Early Childhood Research Quarterly, 23, 141-158. doi: 10.1016/j.ecresq.2007.01.004

Carlson, S. M. (2005). Developmentally sensitive measures of executive function in preschool children. Developmental Neuropsychology, 28, 595-616. doi: 10.1207/s15326942dn2802_3

Carlsson, U., \& Södergård, L. (2014). Att berätta med ord och bilder: Relationen mellan återberättande och bildsekvensering hos barn [To narrate with words and images: The relation between retell and picture sequencing in children]. Unpublished master's thesis, Speech and Language Pathology Unit, Institute of Neuroscience and Physiology and Sahlgrenska Academy, University of Gothenburg. Gothenburg. https://core.ac.uk/download/pdf/43559812.pdf

Clark, C., Wiebe, S., Sheffield, T., \& Espy, K. (2013). Longitudinal associations between executive control and developing mathematical competence in preschool boys and girls. Child Development, 84, 662.

Coady, J. A., \& Evans, J. L. (2008). Uses and interpretations of non-word repetition tasks in children with and without specific language impairments (SLI). International Journal of Language \& Communication Disorders, 43, 1-40. doi: 10.1080/13682820601116485

Dajani, D. R., \& Uddin, L. Q. (2015). Demystifying cognitive flexibility: Implications for clinical and developmental neuroscience. Trends in Neurosciences, 38, 571-578. doi: 10.1016/j.tins.2015.07.003

Diamond, A. (2013). Executive functions. Annual Review of Psychology, 64, 135-168. doi: 10.1146/annurevpsych-113011-143750

Diamond, A., \& Lee, K. (2011). Interventions shown to aid executive function development in children 4 to 12 years old. Science, 333, 959-964. doi: 10.1126/science.1204529

Dick, A. S., Garcia, N. L., Pruden, S. M., Thompson, W. K., Hawes, S. W., Sutherland, M. T., ... Gonzalez, R. (n.d.). No evidence for a bilingual executive function advantage in the nationally representative ABCD study. Nature Human Behaviour, 3, 692-701. doi: 10.1038/s41562-019-0609-3

Doebel, S., \& Zelazo, P. D. (2015). A meta-analysis of the Dimensional Change Card Sort: Implications for developmental theories and the measurement of executive function in children. Developmental Review, 38, 241-268. doi: 10.1016/j.dr.2015.09.001

Duñabeitia, J. A., Hernández, J. A., Antón, E., Macizo, P., Estévez, A., Fuentes, L. J., \& Carreiras, M. (2014). The inhibitory advantage in bilingual children revisited: Myth or reality? Experimental Psychology, 61, 234-251. http://dx.doi.org/10.1027/1618-3169/a000243 
Dunn, L. M., \& Dunn, D. M. (2007). Peabody Picture Vocabulary Test, Fourth Edition (PPVTTM-4). Pearson Education.

ELAN (Version 4.9.4). (2016). Nijmegen: Max Planck Institute for Psycholinguistics. https://tla.mpi.nl/ tools/tla-tools/elan/

Eriksen, H.-L. F., Kesmodel, U. S., Underbjerg, M., Kilburn, T. R., Bertrand, J., \& Mortensen, E. L. (2013). Predictors of intelligence at the age of 5: Family, pregnancy and birth characteristics, postnatal influences, and postnatal growth. PLOS ONE, 8, e79200. doi: 10.1371/journal.pone.0079200

Eriksson, M. (2017). The Swedish Communicative Development Inventory III: Parent reports on language in preschool children. International Journal of Behavioral Development, 41, 647. doi: 10.1177/ 0165025416644078

Eriksson, M., Marschik, P. B., Tulviste, T., Almgren, M., Pérez Pereira, M., Wehberg, S., . . Gallego, C. (2012). Differences between girls and boys in emerging language skills: Evidence from 10 language communities. British Journal of Developmental Psychology, 30, 326-343. doi: 10.1111/j.2044-835X.2011. 02042.x

Fenson, L., Dale, P. S., Reznick, J. S., Bates, E., Thal, D. J., Pethick, S. J., .. Stiles, J. (1994). Variability in early communicative development. Monographs of the Society for Research in Child Development, 59, i-185. doi: $10.2307 / 1166093$

Friend, M., \& Bates, R. P. (2014). The union of narrative and executive function: Different but complementary. Frontiers in Psychology, 5, 469. doi: 10.3389/fpsyg.2014.00469

Fuhs, M. W., \& Day, J. D. (2011). Verbal ability and executive functioning development in preschoolers at head start. Developmental Psychology, 47, 404-416. doi: 10.1037/a0021065

Gabig, C. S. (2008). Verbal working memory and story retelling in school-age children with autism. Language, Speech, and Hearing Services in Schools, 39, 498-511.

Gagarina, N., Klop, D., Kunnari, S., Tantele, K., Välimaa, T., Balcuniene, I., Bohnacker, U., \& Walters, J. (2012). Multilingual Assessment Instrument for Narratives (MAIN). ZAS Papers in Linguistics, 56, 1-115.

Gagarina, N., Klop, D., Kunnari, S., Tantele, K., Välimaa, T., Balcuniene, I., Bonacker, U., \& Walters, J. (2015). Assessment of narrative abilities in bilingual children. In S. Armon-Lotem, J. de Jong, \& N. Meir (Eds.), Methods for assessing multilingual children: Disentangling bilingualism from language impairment. Multilingual Matters.

Gagarina, N., Klop, D., Kunnari, S., Tantele, K., Välimaa, T. Bohnacker, U., \& Walters, J. (2019). MAIN: Multilingual Assessment Instrument for Narratives-Revised. ZAS Papers in Linguistics, 63, 1-36.

Gathercole, S. E., Service, E., Hitch, G. J., Adams, A.-M., \& Martin, A. J. (1999). Phonological short-term memory and vocabulary development: Further evidence on the nature of the relationship. Applied Cognitive Psychology, 13, 65-77.

Gerholm, T., Hörberg, T., Tonér, S., Kallioinen, P., Frankenberg, S., Kjällander, S., Palmer, A., \& Lenz-Taguchi, H. (2018). A protocol for a three-arm cluster randomized controlled superiority trial investigating the effects of two pedagogical methodologies in Swedish preschool settings on language and communication, executive functions, auditive selective attention, socioemotional skills and early maths skills. BMC Psychology, 6, 29. doi: 10.1186/s40359-018-0239-y

Gerholm, T., Kallioinen, P., Tonér, S., Frankenberg, S., Kjällander, S., Palmer, A., \& Lenz-Taguchi, H. (2019). A randomized controlled trial to examine the effect of two teaching methods on preschool children's language and communication, executive functions, socioemotional comprehension, and early math skills. BMC Psychology, 7. doi: 10.1186/s40359-019-0325-9

Gershon, R. C., Wagster, M. V., Hendrie, H. C., Fox, N. A., Cook, K. F., \& Nowinski, C. J. (2013). NIH toolbox for assessment of neurological and behavioral function. Neurology, 80, S2-S6.

Gestsdottir, S., Birgisdottir, F., von Suchodoletz, A., Gunzenhauser, C., Wanless, S. B., Hubert, B., Guimard., P., \& McClelland, M. (2014). Early behavioral self-regulation, academic achievement, and gender: Longitudinal findings from France, Germany, and Iceland. Applied Developmental Science, 18, 90-109. doi: $10.1080 / 10888691.2014 .894870$

Gooch, D., Thompson, P., Nash, H. M., Snowling, M. J., \& Hulme, C. (2016). The development of executive function and language skills in the early school years. Journal of Child Psychology and Psychiatry, 57, 180-187. doi: 10.1111/jcpp.12458

Grissom, N. M., \& Reyes, T. M. (2019). Let's call the whole thing off: Evaluating gender and sex differences in executive function. Neuropsychopharmacology, 44, 86-96. doi: 10.1038/s41386-018-0179-5 
Haman, E., Łuniewska, M., Hansen, P., Simonsen, H. G., Chiat, S., Bjekić, J., ... Armon-Lotem, S. (2017). Noun and verb knowledge in monolingual preschool children across 17 languages: Data from Cross-linguistic Lexical Tasks (LITMUS-CLT). Clinical Linguistics \& Phonetics, 31, 818-843. doi: 10. 1080/02699206.2017.1308553

Haman, E., Łuniewska, M., \& Pomiechowska, B. (2015). Designing Cross-Linguistic Lexical Tasks (CLTs) for bilingual preschool children. In S. Armon-Lotem, J. de Jong, \& N. Meir (Eds.), Assessing multilingual children: Disentangling bilingualism from language impairment (pp. 196-240). Multilingual Matters.

Hansson, K., \& Nettelbladt, U. (2010). Gramba grammatiktest för barn [Gramba grammar test for children]. Studentlitteratur.

Harris, R. J. (2001). A primer of multivariate statistics [Electronic resource]. Lawrence Erlbaum Associates.

Hart, B., \& Risley, T. R. (1995). Meaningful differences in the everyday experience of young American children. Brookes.

Havnes, T., \& Mogstad, M. (2011). No child left behind: Subsidized child care and children's long-run outcomes. American Economic Journal: Economic Policy, 3, 97-129.

Heilmann, J., Miller, J. F., Nockerts, A., \& Dunaway, C. (2010). Properties of the narrative scoring scheme using narrative retells in young school-age children. American Journal of Speech-Language Pathology, 19, 154-166. doi: 10.1044/1058-0360(2009/08-0024)

Hoff, E. (2003). The specificity of environmental influence: Socioeconomic status affects early vocabulary development via maternal speech. Child Development, 74, 1368-1378. doi: 10.1111/1467-8624.00612

Hoff-Ginsberg, E. (1991). Mother-child conversation in different social classes and communicative settings. Child Development, 62, 782. doi: 10.1111/1467-8624.ep9109162253

Howard, S. J., Okely, A. D., \& Ellis, Y. G. (2015). Evaluation of a differentiation model of preschoolers' executive functions. Frontiers in Psychology, 6, 285.

Ibbotson, P., \& Kearvell-White, J. (2015). Inhibitory Control Predicts Grammatical Ability. PLOS ONE, 10, e0145030. doi: 10.1371/journal.pone.0145030

Johnels, J. Å., Hagberg, B., Gillberg, C., \& Miniscalco, C. (2013). Narrative retelling in children with neurodevelopmental disorders: Is there a role for nonverbal temporal-sequencing skills? Scandinavian Journal of Psychology, 54, 376-385. doi: 10.1111/sjop.12067

Karner, M., \&, \& Mattsin, P. (2017). Anpassning av ett ordförrådstest: En reviderad svensk översättning av Peabody Picture Vocabulary Test-IV [Adaption of a vocabulary test: A revised Swedish translation of PPVT-IV]. Unpublished master's thesis, Department of Neuroscience, Division of Speech and Language Pathology, Uppsala University, Uppsala. http://urn.kb.se/resolve?urn=urn:nbn:se:uu:diva339478

Kirkham, N. Z., \& Diamond, A. (2003). Sorting between theories of perseveration: performance in conflict tasks requires memory, attention and inhibition. Developmental Science, 6, 474-476. doi: 10.1111/14677687.00303

Kjellmer, L., Fernell, E., Gillberg, C., \& Norrelgen, F. (2018). Speech and language profiles in 4- to 6-yearold children with early diagnosis of autism spectrum disorder without intellectual disability. Neuropsychiatric Disease and Treatment, 2415.

Klintö, K., Salameh, E., \& Lohmander, A. (2015). Verbal competence in narrative retelling in 5-year-olds with unilateral cleft lip and palate. International Journal of Language \& Communication Disorders, 50, 119-128. doi: 10.1111/1460-6984.12127

Korkman, M., Kirk, U., \& Kemp, S. (2011). NEPSY-II svensk manual [NEPSY-II Swedish manual]. Pearson Assessment.

Kunnari, S., Valimaa, T., \& Laukkanen-Nevala, P. (2016). Macrostructure in the narratives of monolingual Finnish and bilingual Finnish-Swedish children. Applied Psycholinguistics, 37, 123-144.

Labov, W., \& Waletzky, J. (1967). Essays on the verbal and visual arts. In J. Helm (Ed.), Proceedings of the Annual Spring Meeting of the American Ethnological Society, 0748-6995; 1966. The Inst.

Lange, B. P., Euler, H. A., \& Zaretsky, E. (2016). Sex differences in language competence of 3- to 6-year-old children. Applied Psycholinguistics, 37, 1417-1438. doi: 10.1017/S0142716415000624

Lindgren, J. (2018). Developing narrative competence: swedish, swedish-german and swedish-turkish Children Aged 4-6. Acta Universitatis Upsaliensis.

Lindgren, J. (2019). Comprehension and production of narrative macrostructure in Swedish: A longitudinal study from age 4 to 7 . First Language, 0142723719844089. doi: 10.1177/0142723719844089 
Lindquist, B., Persson, E.-K., Uvebrant, P., \& Carlsson, G. (2008). Learning, memory and executive functions in children with hydrocephalus. Acta Paediatrica, 97, 596-601. doi: 10.1111/j.1651-2227.2008. 00747.x

Loeb, S., Bridges, M., Bassok, D., Fuller, B., \& Rumberger, R. W. (2007). How much is too much? The influence of preschool centers on children's social and cognitive development. Economics of Education Review, 26, 52-66. https://doi.org/10.1016/j.econedurev.2005.11.005

Lord C., Rutter M., DiLavore P. C., \& Risi, S. (2000). Autism Diagnostic Observation Schedule (ADOS). Western Psychological Services.

Lundeborg Hammarström, I., Kjellmer, L., \& Hansson, K. (2017). NRDLS-The New Reynell Developmental Language Scales Manual—Swedish version. Hogrefe Psykologiförlaget.

Matthis, T. (1998). Språkprojektet i Farsta/Fagersjö [The language project in Farsta/Fagersjö] in U. Hammare (Ed.). Samverkan för barn och ungdom. En antologi om konsten att bedriva projekt [Cooperation for children and youth: An anthology about the art of running projects] FoU-rapport 1998:4, AWJ Kunskapsförlaget.

Mayer, M. (2003). Frog, where are you? Dial Books for Young Readers.

Marton, K., Kelmenson, L., \& Pinkhasova, M. (2007). Inhibition control and working memory capacity in children with SLI. Psikhologyah: ketav 'et mada'i Yisre'eli le-'iyun ule-mehkar, 50, 110-121. doi: 10.2117/ psysoc.2007.110

McClelland, M. M., Acock, A. C., Piccinin, A., Rhea, S. A., \& Stallings, M. C. (2013). Relations between preschool attention span-persistence and age 25 educational outcomes. Early Childhood Research Quarterly, 28, 314-324. doi: 10.1016/j.ecresq.2012.07.008

McKean, C., Reilly, S., Bavin, E. L., Bretherton, L., Cini, E., Conway, L., ... Mensah, F. (2017). Language outcomes at 7 years: Early predictors and co-occurring difficulties. Pediatrics, 139, 1-10. doi: 10.1542/ peds.2016-1684

Miyake, A., Friedman, N. P., Emerson, M. J., Witzki, A. H., \& Howerter, A. (2000). The unity and diversity of executive functions and their contributions to complex 'frontal lobe' tasks: A latent variable analysis. Cognitive Psychology, 41, 49-100.

Moffitt, T. E., Arseneault, L., Belsky, D., Dickson, N., Hancox, R. J., Harrington, H., ... Caspi, A. (2011). A gradient of childhood self-control predicts health, wealth, and public safety. Proceedings of the National Academy of Sciences, 108, 2693.

Mulder, H., Hoofs, H., Verhagen, J., van der Veen, I., \& Leseman, P. P. M. (2014). Psychometric properties and convergent and predictive validity of an executive function test battery for two-year-olds. Frontiers in Psychology, 5, 733. doi: 10.3389/fpsyg.2014.00733

Noble, K. G., McCandliss, B. D., \& Farah, M. J. (2007). Socioeconomic gradients predict individual differences in neurocognitive abilities. Developmental Science, 10, 464-480.

Odato, C. V. (2013). The development of children's use of discourse like in peer interaction. American Speech, 88, 117-143. doi: 10.1215/00031283-2346825

OECD. (2017). OECD Economic Surveys: Sweden 2017.

Paap, K. R., Johnson, H. A., \& Sawi, O. (2015). Bilingual advantages in executive functioning either do not exist or are restricted to very specific and undetermined circumstances. Cortex, 69, 265-278. doi: 10.1016/ j.cortex.2015.04.014

Pajkin, M. (2014). Socioekonomisk bakgrund och dess betydelse för läsförmåga och betyg [Socioeconomic background and its impact on reading and grades]. Unpublished master's thesis, Department of pedagogy, Linnaeus University. Kalmar Växjö. http://www.diva-portal.org/smash/get/diva2:774443/ FULLTEXT01.pdf

Peristeri, E., Tsimpli, I.-M., \& Tsapkini, K. (2011). linguistic processing and executive control: evidence for inhibition in broca's Aphasia. Procedia: Social and Behavioral Sciences, 23, 213-214. https://doi.org/10. 1016/j.sbspro.2011.09.244

Ramscar, M., Dye, M., Gustafson, J. W., \& Klein, J. (2013). Dual routes to cognitive flexibility: Learning and response-conflict resolution in the dimensional change card sort task. Child Development, 84, 13081323. doi: $10.1111 / \mathrm{cdev} .12044$

R Core Team. (2019). R: A language and environment for statistical computing. R Foundation for Statistical Computing, Vienna, Austria. https://www.R-project.org/ 
Rejnö Habte-Selassie, G., Viggedal, G., Olsson, I., \& Jennische, M. (2008). Speech, language, and cognition in preschool children with epilepsy. Developmental Medicine \& Child Neurology, 50, 432-438. doi: 10.1111/j.1469-8749.2008.02060.x

Renfrew, C. E. (1995). The Bus Story Test: A test of narrative speech (3rd ed.). Speechmark Publishing.

Rindermann, H., \& Baumeister, A. E. E. (2015). Parents' SES vs. parental educational behavior and children's development: A reanalysis of the Hart and Risley study. Learning \& Individual Differences, 37, 133138. doi: 10.1016/j.lindif.2014.12.005

Rueda, M. R., Fan, J., McCandliss, B. D., Halparin, J. D., Gruber, D. B., Lercari, L. P., \& Posner, M. I. (2004). Development of attentional networks in childhood. Neuropsychologia, 42, 1029-1040. doi: 10. 1016/j.neuropsychologia.2003.12.012

Sarsour, K., Sheridan, M., Jutte, D., Nuru-Jeter, A., Hinshaw, S., \& Boyce, W. T. (2010). Family socioeconomic status and child executive functions: The roles of language, home environment, and single parenthood. Journal of the International Neuropsychological Society, 17, 120-132. doi: 10.1017/ S1355617710001335

SCB. (2017). Vanligare med låg ekonomisk standard bland utrikes födda [More common with risk of poverty among foreign-borns]. https://www.scb.se/hitta-statistik/artiklar/2017/Vanligare-med-lag-ekonomiskstandard-bland-utrikes-fodda/

SCB. (2018). Inkomstrapport 2016: individer och hushåll [Income report 2016: Individuals and households]. https://www.scb.se/hitta-statistik/statistik-efter-amne/hushallens-ekonomi/inkomster-och-inkomstfordelning/ inkomster-och-skatter/

Schneider, P., Dubé, R. V., \& Hayward, D. (2005). The Edmonton Narrative Norms Instrument. http:// www.rehabmed.ualberta.ca/spa/enni

Semel, E., Wiig, E. H., \& Secord, W. A. (2003). Clinical evaluation of language fundamentals. Fourth Edition. https://www.pearsonassessment.se/celf-4

SKR. (2018). Fakta förskola [Facts preschool]. https://skl.se/skolakulturfritid/forskolagrundochgymnasieskola/ forskolafritidshem/forskola/faktaforskola.3292.htm

Slot, P. L., \& von Suchodoletz, A. (2017). Bidirectionality in preschool children's executive functions and language skills: Is one developing skill the better predictor of the other? Early Childhood Research Quarterly, 42, 205-214. doi: 10.1016/j.ecresq.2017.10.005

Slotkin, J., Nowinski, C., Hays, R., Beaumont, J., Griffith, J., Magasi, S., Salsman, J., \& Gershon, R. (2012). NIH toolbox, scoring and interpretation guide. National Institutes of Health and Northwestern University.

Song, S., Su, M., Kang, C., Zhang, Y., Shu, H., Liu, H., .. Zhang, Z. (2015). Tracing children's vocabulary development from preschool through the school-age years: An 8-year longitudinal study. Developmental Science, 18, 119-131. doi: 10.1111/desc.12190

Statistics Sweden. (2015). Statistikdatabasen. www.statistikdatabasen.scb.se

Stat Trek: Multicollinearity and Regression Analysis. (n.d.). https://stattrek.com/multiple-regression/ multicollinearity.aspx

Strömqvist, S., \& Verhoeven, L. T. (2004). Relating events in narrative. Vol. 2 Typological and contextual perspectives. Lawrence Erlbaum.

Svensson, Y., \& Tuominen-Eriksson, A. (2002). Bussagan [Bus Story]. Specialpedagogiska Skolmyndigheten Läromedel.

Thordardottir, E. (2011). The relationship between bilingual exposure and vocabulary development. International Journal of Bilingualism, 15, 426-445. doi: 10.1177/1367006911403202

Tomasello, M. (2000). Do young children have adult syntactic competence? Cognition, 74, 209-253. doi: 10. 1016/S0010-0277(99)00069-4

Toplak, M. E., West, R. F., \& Stanovich, K. E. (2013). Do performance-based measures and ratings of executive function assess the same construct? Journal of Child Psychology \& Psychiatry, 54, 131-143. doi: $10.1111 /$ jcpp. 12001

Traverso, L., Viterbori, P., \& Usai, M. C. (2015). Improving executive function in childhood: Evaluation of a training intervention for 5-year-old children. Frontiers in Psychology, 6. doi: 10.3389/fpsyg.2015.00525

Tulsky, D. S., Carlozzi, N. E., Chevalier, N., Espy, K. A., Beaumont, J. L., \& Mungas, D. (2013). V. NIH Toolbox Cognition Battery (CB): Measuring working memory. Monographs of the Society for Research in Child Development, 78, 70-87. doi: 10.1111/mono.12035 
Ursache, A., \& Noble, K. G. (2016). Neurocognitive development in socioeconomic context: Multiple mechanisms and implications for measuring socioeconomic status. Psychophysiology, 53, 71-82.

Vallotton, C., \& Ayoub, C. (2011). Use your words: The role of language in the development of toddlers' self-regulation. Early Childhood Research Quarterly, 26, 169-181

Vissers, C., Koolen, S., Hermans, D., Scheper, A., \& Knoors, H. (2015). Executive functioning in preschoolers with specific language impairment. Frontiers in Psychology, 6. doi: 10.3389/fpsyg.2015.01574

Weiland, C., Barata, M. C., \& Yoshikawa, H. (2014). The co-occurring development of executive function skills and receptive vocabulary in preschool-aged children: A look at the direction of the developmental pathways. Infant and Child Development, 23, 4-21.

Weintraub, S., Dikmen, S. S., Heaton, R. K., Tulsky, D. S., Zelazo, P. D., Bauer, P. J., . . Gershon, R. C. (2013). Cognition assessment using the NIH Toolbox. Neurology, 80, S54-S64.

Westerveld, M. F., \& Vidler, K. (2015). The use of the Renfrew Bus Story with 5-8-year-old Australian children. International Journal of Speech-Language Pathology, 17, 304-313. doi: 10.3109/17549507. 2015.1024168

Wiebe, S. A., Espy, K. A., \& Charak, D. (2008). Using confirmatory factor analysis to understand executive control in preschool children: I. Latent structure. Developmental Psychology, 44, 575-587. http://dx.doi. org.ezp.sub.su.se/10.1037/0012-1649.44.2.575

Wiener, D., Tabor Connor, L., \& Obler, L. (2004). Inhibition and auditory comprehension in Wernicke's aphasia. Aphasiology, 18, 599-609. doi: 10.1080/02687030444000228

Wittenburg, P., Brugman, H., Russel, A., Klassmann, A., \& Sloetjes, H. (2006). ELAN: A professional framework for multimodality research. In Proceedings of LREC 2006, Fifth International Conference on Language Resources and Evaluation.

Wu, K., Chan, S., Leung, P., Liu, W. S., Leung, F., \& Ng, R. (2011). Components and developmental differences of executive functioning for school-aged children. Developmental Neuropsychology, 36, 319-337.

Zelazo, P. D. (2015). Executive function: Reflection, iterative reprocessing, complexity, and the developing brain. Developmental Review, 38, 55-68.

Zelazo, P. D., \& Frye, D. (1998). Cognitive complexity and control: II. The development of executive function in childhood. Current Directions in Psychological Science, 7, 121-126. doi: 10.1111/1467-8721. ep10774761

Zelazo, P. D., \& Jacques, S. (1996). Children's rule use: Representation, reflection, and cognitive control. In R. Vasta (Ed.), Annals of child development: A research annual, 12 (pp. 119-176). Jessica Kingsley Publishers.

Zelazo, P. D., Reznick, J. S., \& Spinazzola, J. (1998). Representational flexibility and response control in a multistep multilocation search task. Developmental Psychology, 34, 203-214. doi: 10.1037/0012-1649.34. 2.203

Cite this article: Tonér, S. and Nilsson Gerholm, T. (2021). Links between language and executive functions in Swedish preschool children: A pilot study. Applied Psycholinguistics 42, 207-241. https:// doi.org/10.1017/S0142716420000703 